\title{
Website disclosure of environmental compliance management-the case of European production companies
}

\author{
Heiko Thimm ${ }^{1}$ (D) $\cdot$ Karsten Boye Rasmussen ${ }^{2}$ \\ Accepted: 8 November 2020 / Published online: 20 November 2020 \\ (C) The Author(s) 2020
}

\begin{abstract}
Companies are expected to comply with environmental laws and regulations. They also face increasing stakeholder interest in information about environmental compliance management efforts. Corporate websites serve today's enterprises as an important medium for voluntary environmental disclosure. However, relatively little research has addressed the topic of environmental compliance management. This empirical study explores current practices of website disclosure of environmental compliance management. Data were collected through a randomly selected sample of 154 European production companies in two groups of medium-sized and very large companies. Environmental management issues concerning the functionalities and disclosure subjects observed on the company websites were recorded. The analyses revealed that in general, corporate websites contain little information about environmental management and environmental compliance management, and large companies disclose more than small companies. The results also indicate that the disclosure practices of some countries deviate remarkably from those of other countries in the sample.
\end{abstract}

Keywords Corporate environmental management - Corporate environmental compliance management · Website disclosure . Organizational sustainability communication $\cdot$ Empirical website observation

\section{Introduction}

The corporate website serves as a relatively inexpensive vehicle for offering up-to-date financial and nonfinancial information to stakeholders and the general public (Jones and Alabaster 1999; Jose and Lee 2007; Qian et al. 2018; Tukker et al. 2009). In the last 10-15 years, the increasing general awareness of environmental concerns has been a main driver of the still growing extent of corporate website environmental information (Hahn and Kühnen 2013; Herzig and Schaltegger 2006). Evidence obtained in various empirical studies has even suggested that today, environmental topics

Heiko Thimm

heiko.thimm@hs-pforzheim.de

Karsten Boye Rasmussen

kbr@sam.sdu.dk

1 School of Engineering, Pforzheim University, Tiefenbronnerstr. 65, 75175 Pforzheim, Germany

2 Department Marketing and Management, University of Southern Denmark, Campusvej 55, DK-5230 Odense M, Denmark are becoming a conventional subject of corporate website publishing (Berthelot et al. 2013; Chaklader and Gulati 2015; Cho and Roberts 2010; Hahn and Kühnen 2013; Isenmann 2004; Jose and Lee 2007; Kim et al. 2010; Zhang et al. 2007).

Various theoretical frameworks, including stakeholder theory (Freeman 2010), agency theory (Jensen and Meckling 1979), and legitimacy theory (Dowling and Pfeffer 1975; Suchman 1995), have been proposed for the explanation of voluntary corporate information disclosure. In particular, legitimacy theory has been widely used as the theoretical underpinning of many scientific studies on environmental disclosure, such as the work of Deegan (2002). Gray et al. (1995) describe reasons for the use of legitimacy theory in the context of disclosure studies. Additionally, an article by Cho and Roberts (2010) contains similar reasons and details about the origin of legitimacy theory from the fields of sociology and social theory.

Major topics of environmental disclosure include corporate values, environmental policies and practices (Jose and Lee 2007), the environmental management system being used (Jose and Lee 2007), environmental initiatives, certificates and awards obtained (Cho and Roberts 2010; Suttipun and 
Stanton 2012), and environmental performance (Ingram and Frazier 1980). Some companies offer downloadable electronic versions of annual environmental reports (Bhasin 2012; Villiers and van Staden 2011; Walden and Stagliano 2003), in which these topics are often addressed.

Recently, new general as well as new specific environmental website topics have gained the interest of the academic world and the interest of environmental organizations and practitioners. In particular, these include sensitive disclosure topics such as environmental performance statistics, ecological footprints at the product level and production site level, and even information about breaches of environmental standards and laws caused by incidents and accidents at production sites and environmental penalties and fines (Ding et al. 2019).

Among the effects of this growing interest in sensitive disclosure topics is the expectation that the work field of corporate environmental compliance management (CECM) (Nicolson 2015; Welch 1998) will gain much more attention in forthcoming years than it currently receives. In fact, CECM specialists expect that their discipline will evolve from a relatively unpopular expert topic to a topic at the center of interest not only for legal authorities but also for many other stakeholders (Aberdeen Group 2011; Ram Nidumolu and Rangaswami 2009).

The general public's growing environmental awareness may in the near future also lead to an extension of corporate environmental disclosure obligations. The already existing traditional legal obligation for environmental compliance disclosure to governmental authorities (European Commission Environment and Climate Regional Accession Network (ECRAN) 2015-2016) may be complemented by a voluntary obligation to publish environmental compliance information on corporate websites (Trabelsi et al. 2008). Already, a growing number of companies publish CECM information in online environmental documents and environmental reports (Thimm and Rasmussen 2019). This tendency has already been addressed in the popular Global Reporting Initiative (GRI) de facto reporting standard (Del Mar Alonso-Almeida et al. 2014; Global Reporting Initiative 2015). More specifically, GRI-307 from 2016 defines the so-called topic-specific disclosure "non-compliance with environmental laws and regulations" (GSSB 2016).

In the existing environmental disclosure research, relatively little attention has been paid to website content about CECM. The extent of CECM disclosure, differences in CECM disclosure across countries and industries, and the determining factors are still largely unknown. Evidence of this knowledge gap is described in a recent literature study (Thimm and Rasmussen 2020). This gap in the research literature is the point of departure for the empirical environmental disclosure study presented in this article. In particular, the study explores the extent of the disclosure of environmental management information and CECM information by small and large companies in European production industries. Additionally, the study investigates websites with respect to specific functional features that can be subsumed under the more general notion of "dialogic communication capabilities" (Atli 2019; Kent and Taylor 1998). The foundation for this study objective is that stakeholders may need to contact corporate environmental management departments and managers for many different reasons. Some contact needs might be urgent. For example, when community members who live in the vicinity of production facilities recognize an uncommon odor, they may want to alert the environmental management department. For that reason, corporate websites are expected to provide communication information. Examples of such information are details about environmental managers (name, picture, short vita), contact information, and a contact function or dedicated notification function that may include a choice of predefined topics. The dialogical communication capabilities of websites may be considered an indication of demonstrated willingness and preparedness to promote and support communication with environmental actors outside the company. The investigation of these options may provide interesting insights into the "green and clean" attitude of companies.

The study operates with four novel formative indices that differ from the indices used by other research groups (Jones and Alabaster 1999; Marston and Polei 2004; Patten and Crampton 2002). Our index construction approach was specialized towards formative indices for statistical data analyses to investigate whether corporate website disclosure addressed specific objectives.

The websites of European production companies were observed during the period from March 15 to April 30, 2019. Companies in European Union member countries must comply with similar bodies of environmental protection laws, regulations, and norms. These homogeneous corporate environmental obligations have been a result of the growing harmonization of legal regulations in the European Union. However, differences between the CECM disclosure practices of companies in different European countries exist owing to the use of different governmental compliance enforcement systems and cultural differences (Gray 1988; Mohamed Adnan et al. 2018; Wanderley et al. 2008).

The overall study approach draws on methods used in other website studies (Cho and Roberts 2010; Gill et al. 2008; Jones and Alabaster 1999; Patten and Crampton 2002) and on experience gained by the authors during several earlier business website studies (Rasmussen and Thimm 2015; Thimm et al. 2016). Principles for the new fields addressed in the study have been adopted from research areas such as research on the dialogical communication features of websites (Atli 2019; Isenmann and Lenz 2001; Kent and Taylor 1998) and work on index construction (Diamantopoulos and Winklhofer 2001). 
It is the goal of the descriptive data analyses to reveal the current CECM disclosure practices of the European production sector. The central characteristics and determining factors of both disclosure of general environmental management and disclosure of CECM are investigated. The data analyses also include investigations of disclosure differences between large companies and small companies. Furthermore, disclosure differences between different countries are explored.

The study results show that to date, only a few companies extensively disclose CECM information on their websites. The great majority of companies do not make full use of the potential for online environmental information provided by websites, nor is full use made of online environmental management information in general or of online focused CECM information.

The next section provides an overview of the relevant research literature. Then, in the third section, the research method is explained, followed by a description of the variables and indices of the study in the fourth section. The descriptive data analyses and results are contained in the fifth section. Conclusions and an outlook are presented in the sixth section.

\section{Literature overview}

One may view the late 1990 s as the early period of the research field of corporate electronic environmental disclosure. Several research groups at that time published study results, including Gray et al. (1995), Deegan and Gordon (1996), Herbst (1998), Jones and Alabaster (1999), and Patten and Crampton (2002). The field has evolved to a more mature research area, and a number of extensive literature reviews have been published, including Berthelot et al. (2003); Hahn and Kühnen (2013); Herzig and Schaltegger (2006); and Thimm and Rasmussen (2020). A recent article by Chiu et al. (2020) is a literature review that focuses especially on environmental disclosure in China.

In an initial step for this article, the current body of literature was searched for published research targeting pertinent articles that are substantially connected to CECM website disclosure. A snowballing approach was performed based on the guidelines of Wohlin (2014). Details about the major snowballing steps were documented to assure the replicability of the review. A set of relevant articles acquired through ad hoc literature searches during the initial research phase was subsequently enlarged by more articles. This approach led to the tentative set of articles used to start the snowballing process, and the start set was enlarged through an interactive literature search. The search steps were performed in the popular bibliographic databases SpringerLink, ScienceDirect, InfoSci-Resources of IGI Global, and Google Scholar. Relevant articles were identified by searching the titles and keywords (i.e., no full text search) of articles published in peer reviewed scholarly journals or proceedings of research conferences with a blind peer review process involving two or more reviewers. More details of the review process and the results have been published in Thimm and Rasmussen (2020).

The results of the literature search indicate that the subject of CECM website disclosure has not yet been extensively investigated by the research community. Only a relatively small number of articles addressed CECM website disclosure. None of these articles focused exclusively on CECM website disclosure. However, these works still offer aspects that are of relevance for this research, as described in the following paragraphs.

In comparison to our sample size of 154 companies, the majority of the studies that are to some degree related to our CECM study were typically based on smaller samples. Of 10 related studies, 8 were based on samples of between 20 and 76 companies, and the remaining two worked with samples of 100 companies (Hassan et al. 2013) and 200 companies (Jose and Lee 2007).

The global cross-industry study of Jose and Lee (2007) explored the disclosure behavior of the 200 largest multinational companies. According to the statistics obtained for the study sample, $29 \%$ of the companies disclosed details of their environmental management system (EMS). Only approximately one-third of these companies addressed office and site practices in their disclosure. Similarly, $31 \%$ of the disclosing companies reported compliance information regarding legal standards.

Cho and Roberts (2010) selected US companies from the national data register of the Environmental Protection Agency (EPA), which is called the Toxic Release Inventory (TRI). The TRI data were used to index companies in terms of their environmental performance. The 100 companies with the highest toxic scores were categorized as "worse environmental performing firms." The other companies were categorized as "better environmental performing firms." Statistical tests of the website data of companies in the two categories lead to interesting findings. The findings support the assumption that "worse environmental performing firms" provide more extensive disclosure in terms of content and website presentation than "better environmental performing firms." In the literature, this kind of corporate behavior is often referred to as "greenwashing" (Siano et al. 2017).

Several similarities to this research and to the study of Cho and Roberts (2010) can be found in the more recent work of Portella and Borba (2020), who used a cross-sectorial sample of 117 listed companies from Brazil and the USA. The researchers created a specific index referred to as the environmental disclosure index (EDI) that explored and measured the extent of disclosure based on 10 categories and 40 subcategories. These categories and subcategories reflected the fact that the researchers conceptualized the study as an environmental accounting study that focused exclusively on content. 
Thus, the categories addressed a broad range of environmental disclosure topics at the detail level. In comparison, the CECM study described in this article operates with a limited number of broad environmental disclosure themes, but the study also explores aspects of information presentation.

Apparently, the great majority of the published environmental disclosure studies focused on the concept of "information content" that Cho and Roberts (2010) described as the extent to which defined themes are textually present in the environmental disclosure. The use of content analysis methods (Russo-Spena et al. 2018) has been proven to be a proper approach to explore the information content of environmental website disclosure. However, several of the identified articles lack details about the content analysis, such as the specific analysis type, the concepts and words themselves and their origin, and the analysis procedure. However, some articles with information about some of these issues can also be found. For example, Jose and Lee (2007) used conceptual analysis, while Suttipun and Stanton (2012) conducted word count analysis. Gill et al. (2008) performed a complex content analysis that combined three approaches: (i) an approach to measure the relative term frequency, (ii) an approach to ascertain the context in which the terms were used, and (iii) an approach to measure the semantic orientation of concepts to determine the direction of sentiment towards the concept. The work of Deegan and Gordon (1996) contained disclosure themes for the investigation of websites that were later adopted, for example, by Suttipun and Stanton (2012). Additionally, Jones and Alabaster (1999) described concepts for website content analyses that were extended with further concepts by Cho and Roberts (2010). Gill et al. (2008) and Berthelot et al. (2013) used the GRI reporting guidelines of the United Nations (Global Reporting Initiative 2015) as a source of disclosure topics.

In general, the investigation of websites in terms of how information is being presented can lead to interesting further insights about CECM website disclosure. Isenmann and Lenz (2001) defined "information presentation" as the extent to which technological, multimedia, and interactive functions are used to enhance the disclosure of environmental information by adding dimensions to plain text narratives. Furthermore, research methods for the analysis of this aspect of electronic environmental disclosure were proposed by Lodhia (2010). While focusing primarily on information content, several disclosure studies also addressed specific aspects of information presentation (Andrew 2003; Bhasin 2012; Cho and Roberts 2010; Jones and Alabaster 1999; Suttipun and Stanton 2012). Our work draws from these research studies, and in addition to its main focus on information content, it also examines the environmental features of websites. In particular, the websites are explored in terms of features that provide the contact data of environmental personnel and enable users to download sustainability documents.
Uncovering the determinants of environmental disclosure behavior has been the objective of a previous few research studies. The research groups performed a range of multivariate analyses with independent variables such as company size, ownership, industry type, firm performance, and media exposure. The statistical model of the environmental accounting study of Portella and Borba (2020) suggested that environmental disclosure in corporate websites can be determined by reviewing the organization size, sector, and country of origin. The third of these factors was evidenced by study results that showed that US companies outperformed Brazilian companies in terms of a special disclosure index.

Multivariate analyses to explore environmental disclosure determinants were also performed by Suttipun and Stanton (2012) based on sample data of Thai listed companies. The analyses led to evidence of relationships between the amount of disclosure and type of industry, ownership status, and audit firm. Berthelot et al. (2013) studied determinants of environmental disclosure by investigating the 68 largest Canadian oil and gas companies. From the obtained results, the researchers concluded that the larger the firm and the greater its media exposure, the more likely it is that sustainability disclosures are provided on the corporate website. Interestingly, the study did not provide evidence confirming a relation between firm profitability and sustainability disclosure on websites. A study that also focused on the national oil and gas sector was conducted by Alawi and Massod (2018), who used a sample of 20 multinational companies operating in Yemen. The researchers employed content analysis methods to investigate the quality of environmental website disclosure and the influence of specific firm characteristics on disclosure quality. Some similarities exist between the website observation methods used in the Yemen study and in this research. For example, in both works, particular website fragments and downloadable reports were excluded from the observation. The Yemen study revealed that the quality of website disclosure among the sample was not high. The authors found that most of the explored environmental aspects were expressed in discursive rather than numerical or monetary terms. A further interesting result of this study is that the regression analyses did not find a significant relationship of a firm's country of origin with disclosure quality.

\section{Research methodology}

The design of this study is based on major principles of website disclosure research. The results of a trial study (Thimm and Rasmussen 2019) and earlier work on website investigations (Rasmussen and Thimm 2015; Thimm et al. 2016) provided guidance for a refinement of these principles. Through this approach, the research design was specialized to the particular goal of exploring the website disclosure of 
CECM. The flow chart in Fig. 1 provides an overview of all the major steps of the study that are described in the subsequent paragraphs. The study limitations are discussed in the last paragraph of this section.

Trial study A trial study was performed (Thimm and Rasmussen 2019) in order to obtain some initial cues about the current status of CECM website disclosure. We also expected to derive helpful insights for the conceptualization of the main study. The sample for the trial study was a subset of the top 25 companies from the Dow Jones Sustainability Index (DJSI) listing for 2018 (Strauss 2018). This approach led to a selection of companies considered to be front-runners in corporate environmental management.

We picked eight companies from seven different countries that belong to the industry categories auto components, communication equipment, industrial conglomerates, electronics instruments and components, automobiles, and electric utilities. According to the North American Industry Classification System (NAICS) (JIST Works 2000), these industry categories are referred to as "environmentally sensitive industries." Due to their good ranking within the DJSI listing and the fact that the DJSI index considers "sustainability information disclosure," a high level of CECM website disclosure was expected among the eight selected companies.
A naive and limited trial study was conducted to quickly explore actual disclosure behavior. Similar to the study of Andrew (2003), a simple content analysis was performed by using the websites' search fields to search for the following terms: environmental compliance, environmental compliance organization, environmental regulations, environmental information system, environmental incident, sustainability information management, and environmental protection. The trial study did not confirm the assumed high level of CECM disclosure for the sample. Moreover, it turned out that the websites neither offered user guidance to systematically explore the company's general efforts in environmental management nor described the company's particular CECM efforts. The trial study proved to be beneficial for the main study, not only by resulting in the general foundation of the study conceptualization but also because the observed low level of website user guidance concerning corporate environmental efforts inspired us to explore dialogical communication capabilities. Furthermore, the experience with the search terms proved to be helpful for the specification of search terms for the main study. Additionally, among the trial study sample, a single company was identified that served as a benchmark in the main study because of its outstanding extent of disclosure of environmental information.
Fig. 1 Overview of the major study steps

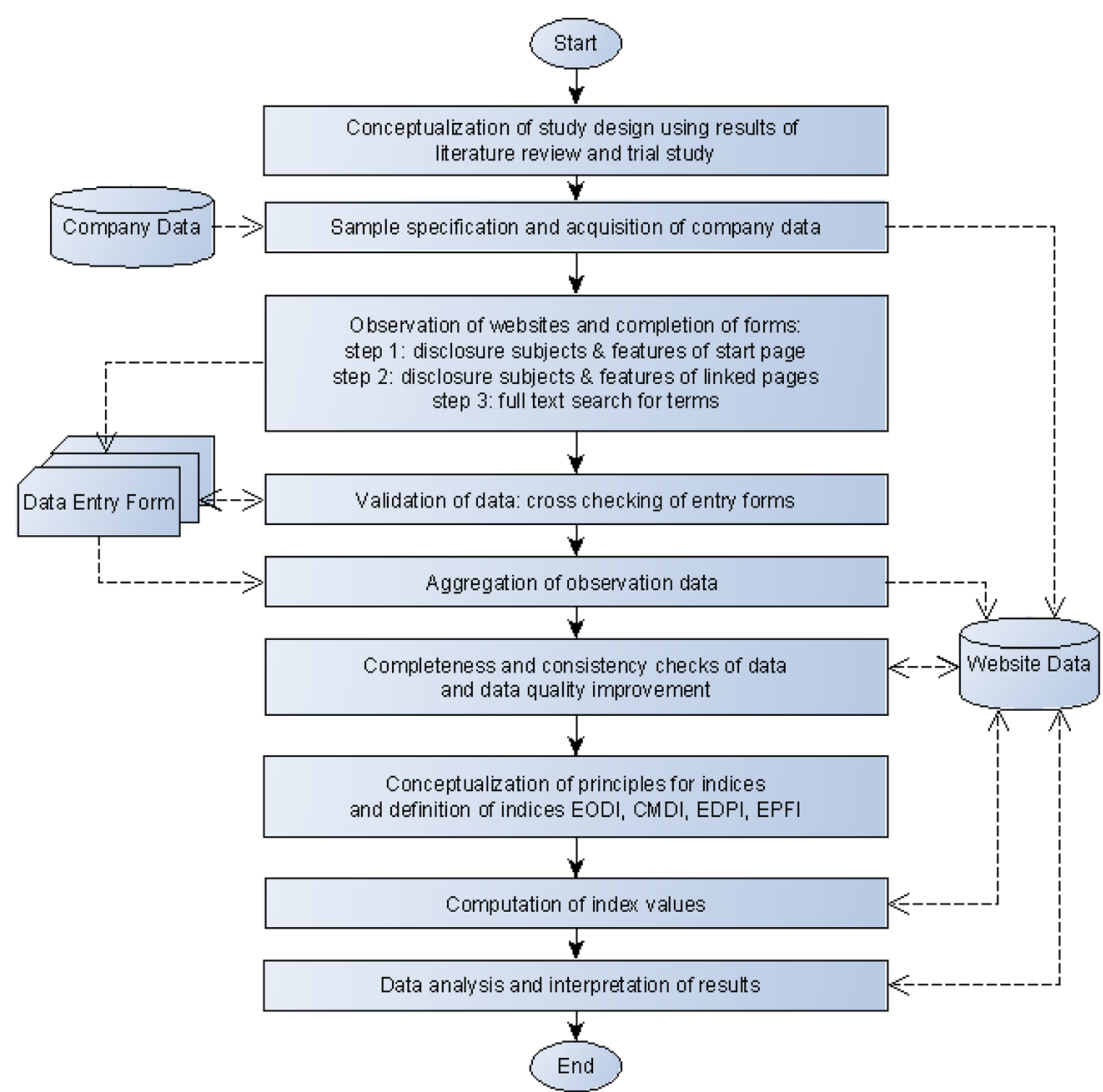


Construction of the study sample The target population of the main study is implied by our research focus on European production companies. Consequently, companies from distinct industry sectors and of distinctly different sizes were selected based on the European Classification of Economic Activities, which is also known as NACE (European Commission 2008):

- A European company was defined as a company with its base in a country among the 28 member countries of the European Union (including the UK).

- A production company was defined as a company with the particular codes 13 to 16 and 22 to 31 among its primary NACE codes (NACE Code Standard, NACE Rev. 2).

- Company size: For comparison, we wanted two groups of companies:

- Large: Large companies with more than 10,000 employees

- SME: Small or medium-sized enterprises, particularly medium-sized enterprises with at least 125 and a maximum of 249 employees

A strict definition of an SME involves not only the number of employees but also financial information (European Commission 2015). However, because financial information could be missing and/or not up-to-date for all companies, the simple definition based exclusively on the number of employees was applied in its often-used simple form. In the analysis, we refer to large companies as "large" and medium-sized companies as "SMEs."

The selection of the population was performed in the Global Company Database ORBIS (Bureau van Dijk 2019). The population consisted of 12,829 companies, of which 216 were large companies. Among the large companies, 80 were randomly selected. This sample comprised of companies from the following 13 countries: Austria, Belgium, Denmark, Finland, France, Germany, Ireland, Italy, Luxembourg, the Netherlands, Spain, Sweden, and the UK.

The SMEs were then also limited to companies from the same 13 countries, which meant that the population was 8499 . Of these, 80 SMEs with 125 or more employees were randomly selected. The sample thus consisted of 160 companies. Of these, data for 6 companies were unobtainable. The tabulation (Table 1) shows the distribution among countries and the sizes of the companies.

Data collection method Data for the sample companies' websites were collected based on a data collection form. Comprehensive instructions about the study items were given to promote a clear understanding of both the targeted website part and the data recording in the form. The data collectors also received intense face-to-face training. In addition to recording the observation results, the data collectors addressed
Table 1 Distribution of the study sample companies among countries and company sizes

administrative data, including the company ID, the website address, the evaluator's name, and a timestamp. The data collection was performed by 164 assistants from March 15 to April 30, 2019. Each team of 4-5 assistants was randomly assigned 5-6 websites to be jointly evaluated by at least two team members. A moderated online forum and an online FAQ were made available to allow for the speedy resolution by the study leaders of questions or issues that needed clarification.

The data collectors were advised to conform to several general guidelines, including the use of a specific browser type and version (Mozilla Firefox), acceptance of cookies, validation of the correctness of the opened website, and the choice of the English-language option at the website. Note that the last of these rules included the fact that a localized website might have to be opened for a global company that served as an umbrella for a set of country-specific incarnations.

Observation steps and observation items Figure 2 illustrates the approach devised to observe (i) the general level of website disclosure of environmental management and (ii) the disclosure of CECM, which, as described above, is considered a specific subarea of corporate environmental management. The focus on the extent of disclosure in these two areas was exercised through corresponding sets of specified disclosure subjects. As described in more detail below, disclosure subjects were specified that were a good fit for the theme of environmental management and CECM.

The observation approach was also tailored to explore websites with respect to (iii) dialogical communication capabilities for website visitors specifically seeking company- 
Fig. 2 The three-step website observation approach

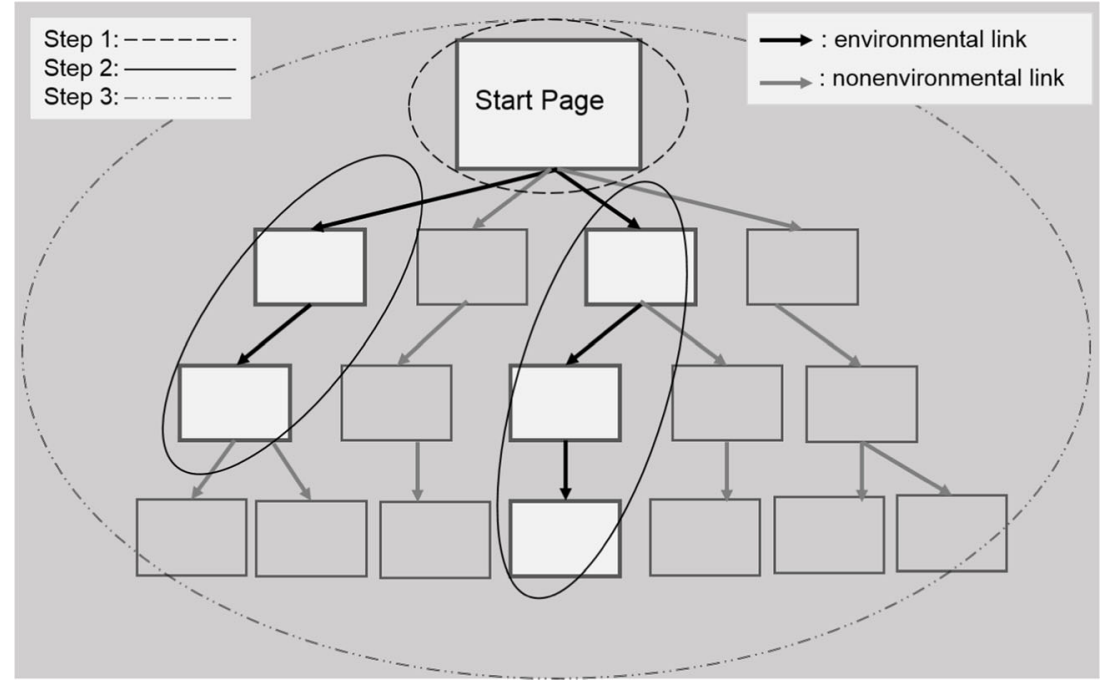

specific environmental management information, including information about CECM. In particular, the approach targeted website features that allow fast and easy access to environmental information as well as features related to contacting the company with respect to environmental concerns.

In three observation steps, the disclosure subjects of the above-described study goals (i) and (ii) and the environmental website features at the center of the study goal (iii) were explored as follows:

- Observation step 1 was performed with the goal of exploring and recording the existence of environmental features and disclosure subjects at the start page.

- Observation step 2 also examined environmental features and disclosure subjects, but the search space was dynamically derived through a restricted top-down website traversal of "environmental links" with departure from the start page. The environmental links were identified as menu items or hypertext links that carried environmental information in the content area of the start page. Each link established a new traversal starting point for a further potential traversal path. As opposed to "ordinary links," environmental links are defined as links where relevant content is implied by the link name or context. Furthermore, only links internal to the investigated website were accepted. Consequently, the traversal was terminated when a page without environmental links was reached. Without the termination condition, the observers would have faced the impossible task of inspecting every individual page of the entire website, which in the case of large companies would easily have led to tens of thousands of pages to be inspected.

- In observation step 3, the observers had to perform a set of full text searches for specific terms used to describe major aspects of the work field of environmental management and CECM. An ideal method for obtaining a proper set of search terms would have been choosing terms from a globally accepted ontology for the area of corporate environmental management. However, such an ontology seemingly still does not exist. Therefore, the search terms were obtained through a less rigid method. Based on a thorough review of the corresponding literature, a best effort selection of 29 search terms was completed. Note that substantial expertise available in the research team from working with industry experts and practitioners for more than 8 years could be leveraged for this task. The full text searches for the terms were performed with Google advanced search with the search space restricted to the domain of the corresponding corporate website.

Each observation item was associated with a separate observation variable, which led to a total set of more than 250 variables. The specific subset of variables focused on in this article is described in the next section. Most of the questions addressed in the first two observation steps can be generalized as "Feature or disclosure subject observed?". Obviously, these questions had to be answered by recording either 1 (=yes, observed) or 0 (=not observed) as the variable value. Some of the questions were directed at names, titles, labels, and web addresses that allowed multiple responses through comma-separated values. The number of hits was recorded for the search terms without counting advertising links. Furthermore, the top five web addresses that referred to $\mathrm{html}$ pages - excluding advertisement URLs - were captured from the list of hits that were returned and ordered by the search engine. The recording of the URLs enabled data quality-checking procedures.

Validation of observation data and processing steps to obtain the final dataset After all available websites were evaluated, a first validation step was performed. Sixty randomly selected data collection forms were distributed among the 30 evaluator teams through a method that excluded the original team. Each team was assigned the task of validating the completeness and 
correctness of the observation data that had been acquired by 2 other teams. The teams were instructed to contact the original observers if the validation did not confirm the original observation data. The originators were instructed to check the validators' objections, decide whether there was a need for corrections, and possibly perform required revisions. After the validation, we had a set of 158 completed observation forms - 2 companies no longer existed — of which 24 forms underwent minor revisions. The observation data were extracted from the forms and transformed into a tabular and machine-processible format. The resulting table with all observed data underwent several data integrity and consistency checks. These checks revealed missing entries, including missing web addresses, and extraordinarily large values for the number of hits for search terms, indicating that the defined search procedure most likely had not been followed carefully. All detected data quality deficiencies were reported to the responsible original data collectors, who then provided correspondingly revised data. The necessary data revisions according to the observation team's feedback were performed by one of the study leaders. In this process, four additional companies were excluded because they turned out not to be production companies. A final collection of observation data for 154 corporate websites was obtained.

Study limitations Even though data quality assurance measures were performed, a fundamental limitation exists: The inability to identify disclosure data on a website cannot be viewed as hard evidence of nondisclosure because of several potential sources of fuzziness. For example, the targeted observation items may have been hosted at a location that was not part of the website exploration path, the items might have been added to the website after the initial data collection was performed, the Google search engine might have had functional problems, or an outdated search index might have been used. The fact that the investigation focused explicitly on html pages might represent a further limitation. This methodology is, however, used in several other disclosure studies (Cho and Roberts 2010; Patten and Crampton 2003) because the inclusion of graphical website artifacts, such as scanned pages, pictures, illustrations, animations, and videos, imposes many challenges for "manual" disclosure analyses and would require special software tools for website content analysis. Inclusion of PDF documents in website disclosure research, in most cases, also requires special content analysis software. In particular, software is needed that is able to explore documents that have been created with different PDF versions and different access permissions (e.g., searchable and nonsearchable). Without such special software, one would need to spend excessive time following hyperlinks across the website. Limitations due to human factors during the inspection and recording process (e.g., tiredness, poor concentration) are assumed to have little impact on the study because of the various counteracting measures.

\section{Variables and indices}

Data for 154 corporate websites were obtained through the above-described study steps. More than 250 properties (with each property being associated with a corresponding variable) of each observed website were encoded. Some of the variables were previously observed in the empirical investigations of Cho and Roberts (2010), Jones and Alabaster (1999), and Patten and Crampton (2002).

Formative indices have been used in many website disclosure studies (Bonson and Escobar 2002; Cho and Roberts 2010; Clarkson et al. 2008; Deegan 2002; Kosajan et al. 2018). This research also applied formative indices built from specific observation variables according to theoretical foundations for the construction of multi-scale measures (Diamantopoulos and Winklhofer 2001). Furthermore, principles of index construction described in related disclosure studies (Jones and Alabaster 1999; Marston and Polei 2004; Patten and Crampton 2003; Portella and Borba 2020) were also adopted.

In the final study steps (Fig. 1), three indices were built from distinct sets of variables, and a summary index was also constructed. Table 2 contains the four indices that served as analytical instruments tailored to this study's specific research objectives. The EODI and the CMDI focused on the extent of disclosure of environmental management and compliance management. The EPFI measured environmental dialogical communication capabilities. Companies may use these capabilities to signal awareness of environmental concerns. The EDPI measured websites from all of the perspectives of the three former indices. That is, the EDPI serves as a combined index that measures the extent of website disclosure and the extent of website dialogical capabilities.

The index scores (scalar values) for the websites were computed for the EODI, the CMDI, and the EPFI through the same general calculation approach. The scores were determined by an accumulation of the weighted values of the observation variables associated with the index. EDPI scores were computed through the formula EDPI $=$ EODI + CMDI + EPFI.

The chosen variable weights of the indices conformed to two pragmatic rules intended to compensate for otherwise occurring bias effects. Rule 1: The variables that referred to features and disclosure subjects at the start page were assigned higher weights than their counterparts that referred to lowerlevel pages of the website. Rule 2: The variables that referred to the search terms were equally assigned degrading weights of 0.1. This degradation approach reflected the fact that the great majority of the obtained hits in reality did not refer to web pages with extensive environmental management disclosure. Despite this limitation, the number of hits still indicated the merit of the study. For this reason, the degradation approach was applied instead of eliminating the hit frequencies. 
Table 2 The four formative indices defined for this study

\begin{tabular}{|c|c|c|}
\hline Index & Description & Score calculation \\
\hline $\begin{array}{l}\text { EODI-Environmental } \\
\text { Management Overview } \\
\text { Disclosure Index }\end{array}$ & $\begin{array}{l}\text { Extent of overview information of the company's general } \\
\text { environment management engagement }\end{array}$ & $\begin{array}{l}\text { Accumulation of weighted observation } \\
\text { variables associated with the index (see } \\
\text { Table } 3 \text { and Table } 4 \text { ) }\end{array}$ \\
\hline $\begin{array}{l}\text { CMDI-Compliance } \\
\text { Management Disclosure Index }\end{array}$ & $\begin{array}{l}\text { Extent of information focused on the company's environmental } \\
\text { compliance management efforts }\end{array}$ & \\
\hline $\begin{array}{l}\text { EPFI-Environmental } \\
\text { Presentation Features Index }\end{array}$ & $\begin{array}{l}\text { Extent of dialogical communication capabilities through website } \\
\text { features such as contact options and specific information about } \\
\text { environmental management }\end{array}$ & \\
\hline $\begin{array}{l}\text { EDPI-Environmental } \\
\text { Disclosure and Presentation } \\
\text { Index }\end{array}$ & $\begin{array}{l}\text { Extent of targeted environmental website disclosure and extent of } \\
\text { website dialogical capabilities }\end{array}$ & $\begin{array}{l}\text { Accumulation of the scores of the previous } \\
\text { indices }\end{array}$ \\
\hline
\end{tabular}

Distinctive sets of variables served as the foundation for the formation of the indices. The variables are contained in Table 3 and Table 4 . The rightmost three columns of the tables display how the variables are associated with the particular index. Only when a numeric value is given is the respective variable associated with the index. The numeric value is considered in the index formula as the weight of the variable. For example, the variable coded "F1_location," which is assigned a value of 2.0, belongs to the set of variables that determine the EPFI. However, the same variable is not used in the other index calculation formulas. The above-described pragmatic rules for the tailoring of the variable weights are reflected in the weights. For example, the variables "F5_news" and "P1_news" are assigned a 1.5 weight and a 1.0 weight, respectively. The higher weight reflects an environmental news section at the start page most likely being more easily noticed by ordinary website visitors than a news section at a lower-level web page.

The details of Table 3 include the particular website observation item (labeled "OI") that the variable refers to. The label "SP" indicates a reference to the start page (observation step 1), whereas the label "LP" signifies the above-described top-down traversal of environmental links (i.e., linked pages, step 2).

The observation task implied by the variables of Table 3 was meant searching for the targeted website items and assigning one of two possible values: " 1 " for item found and " 0 " for item not found. However, in addition to the binary variables in Table 3 , there are numeric variables that were originally assigned numbers. These numbers signify how many instances of a particular observation item were provided at the website (e.g., number of downloadable environmental reports). We intend to make use of the original number values in future data analyses that will address particular aspects of environmental disclosure. Since this research targets a broad view of environmental website disclosure, the numeric variables were transformed into binary variables to obtain a homogeneous set of dichotomous variables coded 0 and 1 . If a variable had a value larger than 1 , the variable was assigned the value 1 . Otherwise, no transformation was applied to the variable. The fourth column of Table 3 signifies through the label "t," the variables for which this transformation procedure was performed.

Table 4 contains the variables used for the full text search performed in observation step 3. Every variable refers to a search term such as "environmental management activity" that is referred by variable T11. The number of search hits originally coded in the variables was transformed into binary values (i.e., 1 for one or more hits and 0 otherwise). This transformation was applied for the same reasons described above for the transformation of the variables that initially were defined as nonbinary.

\section{Descriptive study results}

The section above demonstrates that this study strives to uncover major characteristics of European production companies' current disclosure concerning general environmental management and environmental compliance management. In particular, variations in companies' disclosure are investigated. The large companies of the complete sample were compared to the SMEs. The companies' disclosure is also compared at the country level. Even though at this stage of our research, the study is intended to be mainly descriptive in nature, the data analyses are also aimed at uncovering possible determining factors of environmental management disclosure and CECM disclosure. Additionally, the data are used to investigate how CECM disclosure and dialogical communication capabilities are influenced by the disclosure of general environmental management.

The three subsequent sections describe the data analyses that make use of the above-defined indices. The findings, such as disclosure differences between large companies and SMEs or between different countries, can be influenced by many 
Table 3 Variables that refer to website items observed in steps 1 and 2

\begin{tabular}{|c|c|c|c|c|c|c|}
\hline Variable code & Description & $\mathrm{OI}$ & $\mathrm{T}$ & Overview EODI & Compliance CMDI & Features EPFI \\
\hline F1_location & Left menu contains environmental item & SP & - & - & - & 2.0 \\
\hline F2_location & Top menu contains environmental item & SP & - & - & - & 2.0 \\
\hline F3_location & Right menu contains environmental item & SP & - & - & - & 2.0 \\
\hline F4_location & Bottom menu contains environmental item & SP & - & - & - & 2.0 \\
\hline F5_news & Environmental news section & SP & - & - & - & 1.5 \\
\hline P1_news & Environmental news section & LP & - & - & - & 1.0 \\
\hline F6_notification & Notification function & SP & - & - & - & 1.5 \\
\hline F7_linked_notification & Linked notification function & SP & - & - & - & 1.5 \\
\hline P2_notification & Notification function & LP & $\mathrm{t}$ & - & - & 1.0 \\
\hline F8_sections & Environmental sections & SP & $\mathrm{t}$ & - & - & 1.5 \\
\hline F9_environmental_links & Linked environmental pages & SP & $\mathrm{t}$ & - & - & 1.5 \\
\hline F10_reports & Downloadable environmental reports & SP & $\mathrm{t}$ & - & - & 1.5 \\
\hline P3_reports & Downloadable environmental reports & LP & $\mathrm{t}$ & - & - & 1.0 \\
\hline F12_training & Environmental training material & SP & - & - & - & 1.5 \\
\hline P4_training & Environmental training material & LP & - & - & - & 1.0 \\
\hline F13_persons & Names of environmental personnel & SP & - & - & - & 1.5 \\
\hline P5_persons & Names of environmental personnel & LP & - & - & - & 1.0 \\
\hline F13c_contact & Contact info of environmental personnel & SP & - & - & - & 1.0 \\
\hline P6_contact & Contact info of environmental personnel & LP & - & - & - & 0.5 \\
\hline F13b_blogs & Blogs of environmental personnel & SP & - & - & - & 1.0 \\
\hline P7_blogs & Blogs of environmental personnel & LP & - & - & - & 0.5 \\
\hline S1_certificates & Environmental certificates & $\mathrm{SP}$ & $\mathrm{t}$ & 1.5 & - & - \\
\hline L1_certificates & Environmental certificates & LP & - & 1.0 & - & - \\
\hline S2_awards & Environmental awards & SP & $\mathrm{t}$ & 1.5 & - & - \\
\hline L2_awards & Environmental awards & LP & - & 1.0 & - & - \\
\hline S3_audits & Environmental audits & SP & - & - & 1.5 & - \\
\hline L3_audits & Environmental audits & LP & - & - & 1.0 & - \\
\hline S4_partners & External environmental partners & SP & - & 1.5 & - & - \\
\hline L4_partners & External environmental partners & LP & - & 1.0 & - & - \\
\hline S5_compliance & Phrase "environmental compliance management" & SP & - & - & 1.5 & - \\
\hline L5_compliance & Phrase "environmental compliance management" & LP & - & - & 1.0 & - \\
\hline S6_measures & Measures to enforce environmental compliance & SP & - & - & 1.5 & - \\
\hline L6_measures & Measures to enforce environmental compliance & LP & - & - & 1.0 & - \\
\hline S7_negative & Negative environmental information & SP & - & - & 1.5 & - \\
\hline L7_negative & Negative environmental information & LP & - & - & 1.0 & - \\
\hline S8_ict & Use of ICT for environmental mgmt. & SP & - & 1.5 & - & - \\
\hline L8_ict & Use of ICT for environmental mgmt. & LP & - & 1.0 & - & - \\
\hline
\end{tabular}

Explanations of columns: Observation item (OI) is either start page (SP) or linked pages (LP); a transformation (t) is applied; the three rightmost columns indicate which variables are used with which weights for the Environmental Management Overview Disclosure Index (EODI), Compliance Management Disclosure Index (CMDI), and Environmental Features Index (EPFI)

aspects, such as differences in countries' business ecosystems, differences in business culture, and differences in countries' environmental protection enforcement structures. Therefore, these sections primarily describe facts about the status of website disclosure of the study sample and only rarely elaborate on possible causes of certain findings. The fourth subsequent section contains remarks about sustainability communication practices observed through the website inspection process.

\section{Environmental management website disclosure}

As a summary index, the EDPI serves as a general measure of the environmental disclosure of the target group's websites by 
Table 4 Variables that refer to search terms used in step 3 of the website observation

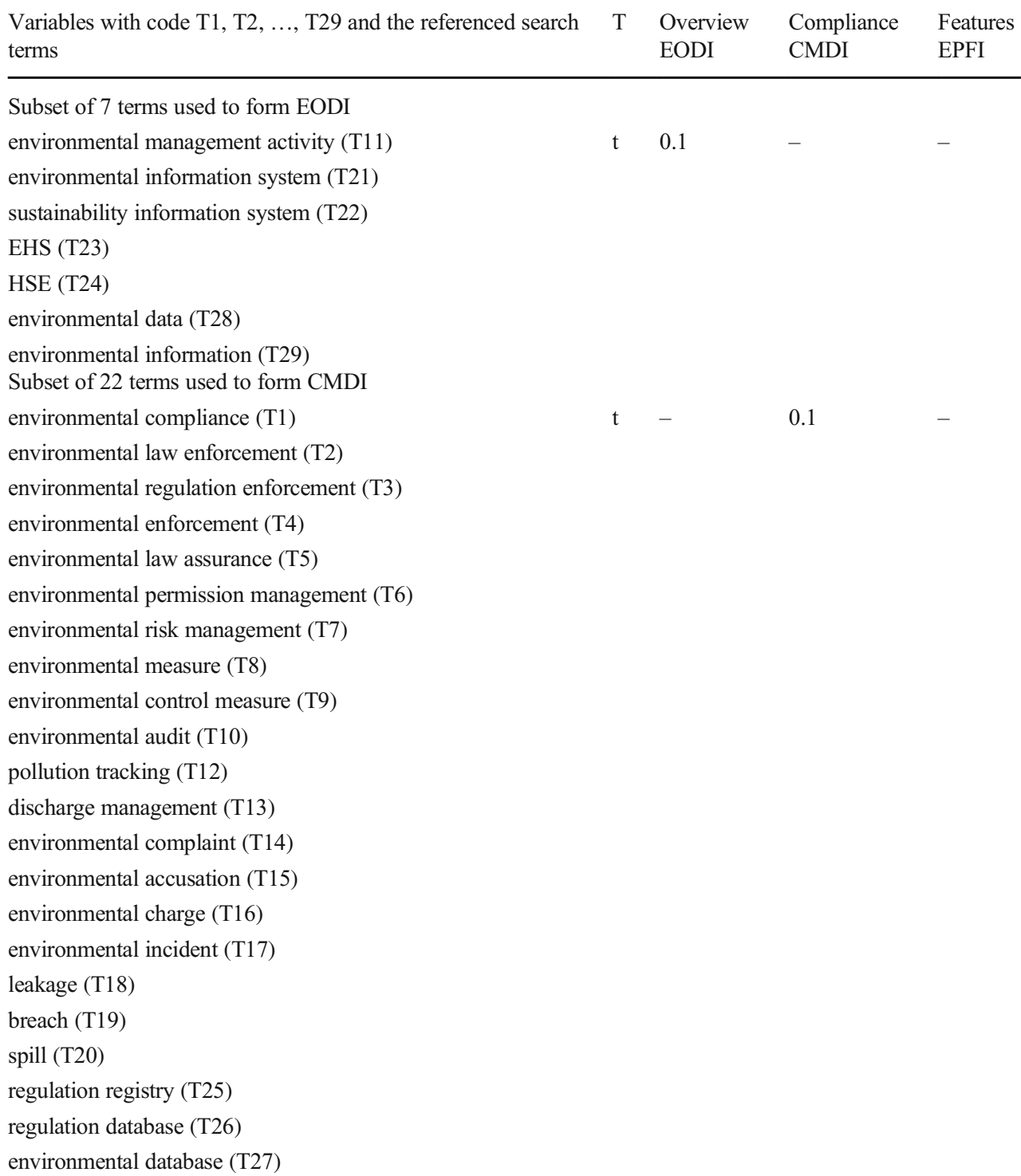

Explanations of columns: Transformation ( $\mathrm{t}$ ) is applied; the three rightmost columns indicate which variables - in addition to those listed in Table 3 - are being used with which weights for the Environmental Management Overview Disclosure Index (EODI), Compliance Management Disclosure Index (CMDI), and Environmental Features Index (EPFI) aggregating the extent of disclosure of environmental management (EODI), extent of CECM disclosure (CMDI), and extent of dialogical communication capabilities (EPFI).

With respect to the sample set of companies, the box-andwhisker plots in Fig. 3 show the distribution of the EDPI by company size. The boxes depict the middle $50 \%$ of the observations. A box's middle line signifies the median. The calculated mean is depicted by a diamond. From Fig. 3, two major characteristics of environmental disclosure practices can be derived. First, the companies fell far short of the maximum possible EDPI value of 49.9, as the highest EDPI score was only 26. The statistics show that the majority of the companies disclose environmental information to a relatively small extent. For the SMEs, the 25 th percentile had a score of 0 . It is no surprise that due to the limited financial power of SMEs, we observed an overall EDPI score for them that was significantly smaller than the score observed for large companies. Our findings confirm that the company size is one of the determining factors of environmental disclosure in general, which has been revealed in earlier studies (Berthelot et al. 2013; Bonson and Escobar 2002; Clarkson et al. 2008; Deegan and Gordon 1996).

Figure 4 shows the distribution of the EDPI by the countries covered in the sample. For every country, the box is assigned an individual width. The width of a box is 
Fig. 3 Distribution of the EDPI by company size

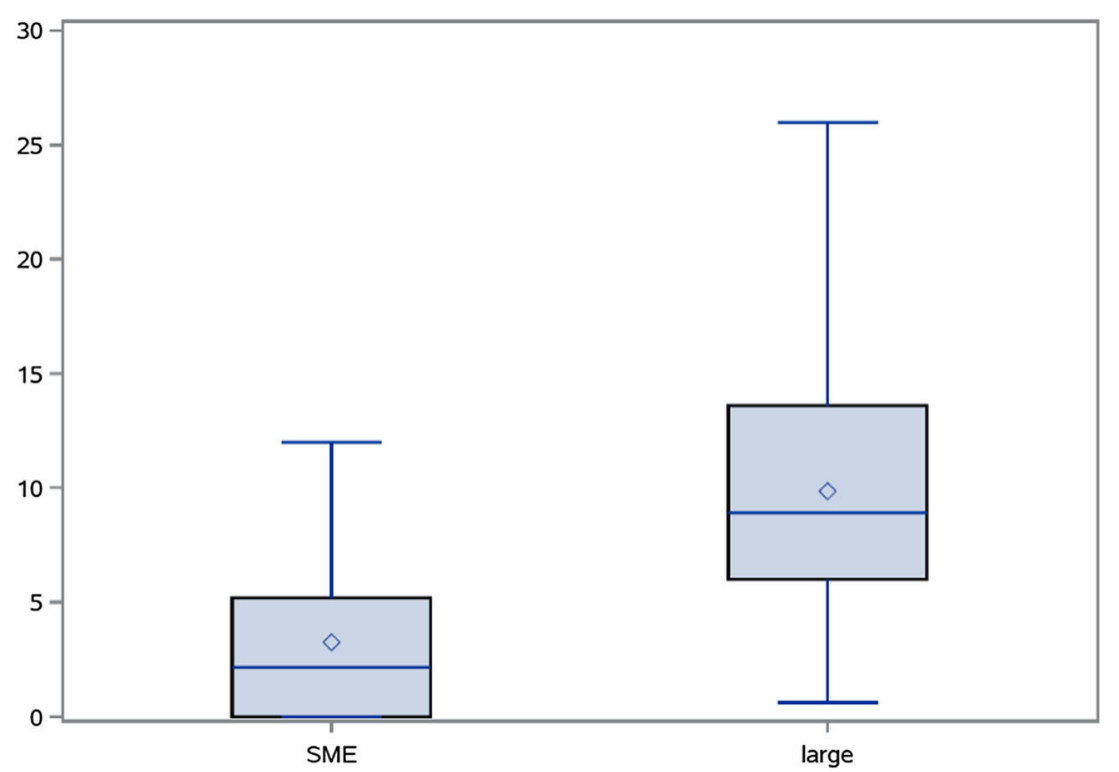

proportional to the number of companies (contained in the sample set) of that country. Thus, the German companies (52 companies) have the widest box, whereas the companies from Belgium and Denmark have the narrowest boxes ( 3 and 2 companies, respectively). The mean of all groups lies within a range of 3 and 9 points. The companies from Luxembourg, the Swedish companies, and some companies from smaller countries perform better than the others with respect to the EDPI. When grouping the smaller countries separately to reflect that only a small number of observations are available for each of them (see Fig. 5), the top performance by Swedish companies becomes slightly more clear.

The comparison between the large companies and the SMEs revealed that large companies achieve higher EDPI scores than SMEs. We used corresponding data analyses to investigate whether this gap exists for all countries of the sample. As evidenced in Fig. 6 and Fig. 7, the large companies outperform the SMEs in all countries except the UK. The UK numbers in Fig. 7 show that the EDPI scores of the large companies are very similar to those of the SMEs. The chart also shows that the Swedish companies achieve the highest EDPI scores in both the group of large companies and the group of SMEs. A "close race" in terms of EDPI scores can be observed for companies from Italy, Austria, the Netherlands, and Germany in both size categories.

\section{CECM website disclosure}

As the statistics described below indicate, only a small amount of CECM information was found at the target group's
Fig. 4 Distribution of the EDPI by country

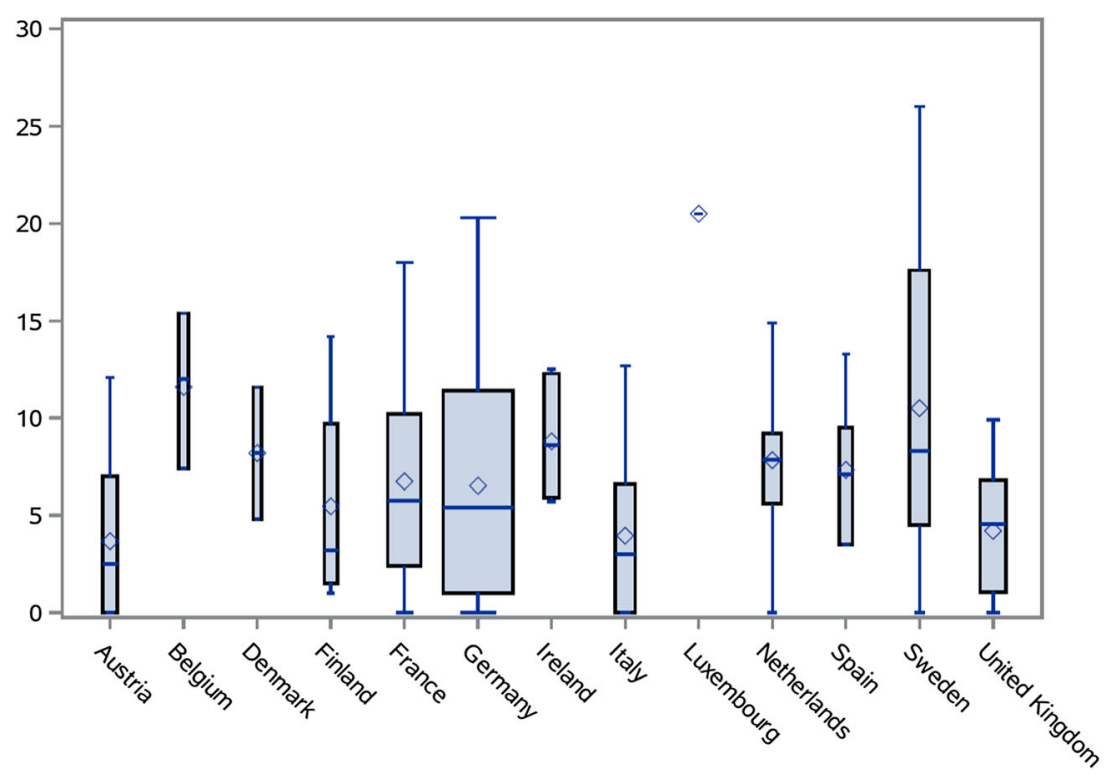


Fig. 5 Distribution of the EDPI by country with grouping of small countries

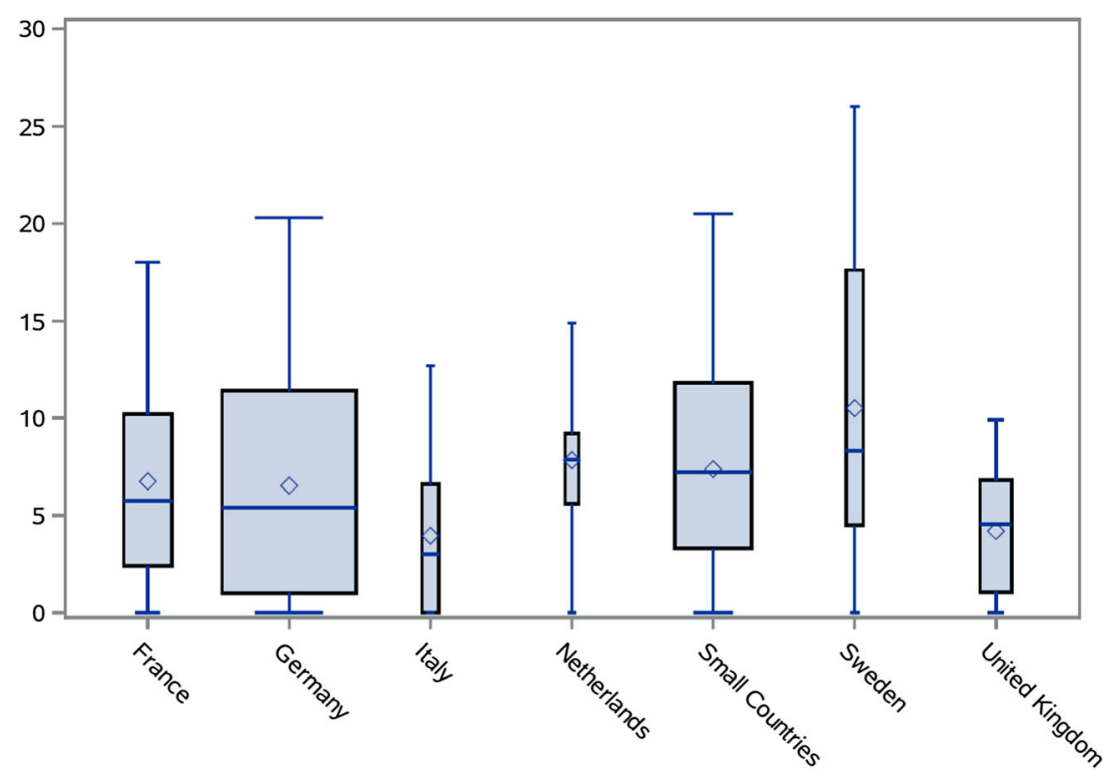

websites. Websites that contained any CECM information often presented only short general statements about the company's CECM commitment. Visitors looking for CECM information were referred by some websites to corporate sustainability reports. A small number of the websites offered hyperlinks to online versions of the reports.

CECM disclosure is now being described in detail through statistics in the CMDI. The distributions of the CMDI for the large companies and the SMEs are shown in the box plots of Fig. 8. Considering that the maximum potential CMDI score is 14.2 , the plots reveal that the great majority of the companies have a low score. In particular, the SMEs disclose almost nothing about their CECM efforts, as evidenced in Fig. 8 by a mean value close to 0 . This variation in CMDI scores may be caused by the fact that large companies, due to their size and global presence, usually need to deal with a larger body of legal regulations than SMEs. However, as described in the subsequent paragraphs, our data analyses also suggest that more environmental regulations do not necessarily lead to a greater extent of CECM disclosure. The difficult situation of dealing with many different legal environmental regulations may mislead large companies to choose more cautious CECM disclosure practices.

When comparing the CMDI distribution for large companies and SMEs (Fig. 8) with the corresponding EDPI distribution (Fig. 3), an interesting difference can be found. Surprisingly, the CECM disclosure gap between the disclosure of large companies and that of SMEs is smaller than the gap for general environmental disclosure, as indicated by the EDPI scores.
Fig. 6 Distribution of the EDPI by company size and country

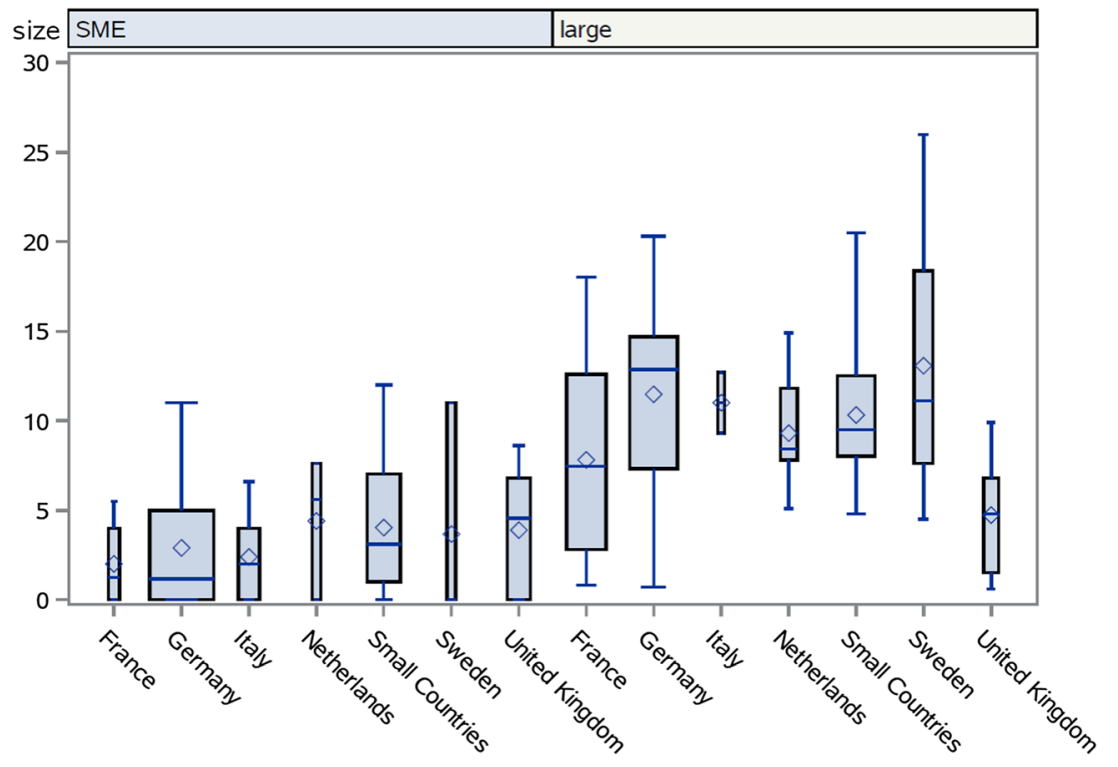


Fig. 7 Distribution of the EDPI by country and company size

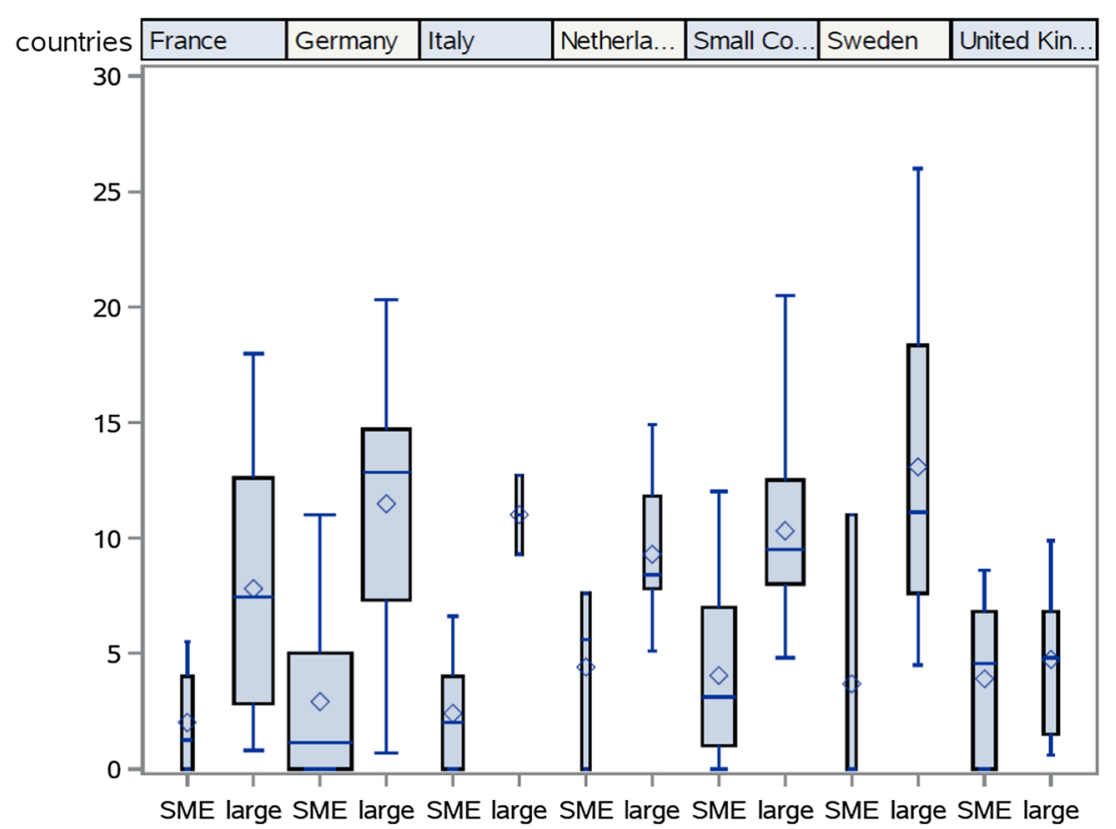

For the EDPI (Fig. 3), a small gap exists between the middle 50th percentile of the SMEs and the middle 50th percentile of the large companies. This gap indicates that all large companies of the middle 50th percentile achieved a higher EDPI score than the best EDPI score of the middle 50th percentile of the SMEs. The significantly higher extent of EDPI disclosure of the large companies is also indicated by the mean values of approximately 9 for large companies and approximately 3 for SMEs.

A comparison of the statistics for the CMDI yields two further insights into CECM disclosure practices. First, the large companies' mean value of 1.2 is only approximately two times higher than the SMEs' mean value of approximately 0.6 . Second, as shown in Fig. 8, the two 50th percentiles even slightly overlap. That is, the lowest-performing large companies of the middle $50 \%$ are outperformed by the topscoring SMEs of the middle 50\%. Apparently, the CECM disclosure of some large companies is more limited than the CECM disclosure of some SMEs.

The limited CECM disclosure of the low-scoring large companies may be caused by various reasons. Deficiencies of the environmental compliance management organization are a possible reason. Another and less extreme reason is that the low-scoring companies may not yet be fully aware of the general public's increasing interest in CECM information.

Figure 9 presents the distribution of the CMDI by all countries of the sample. Figure 10 contains a revised version of the box plot chart in which the smaller countries are aggregated
Fig. 8 Distribution of the CMDI by company size

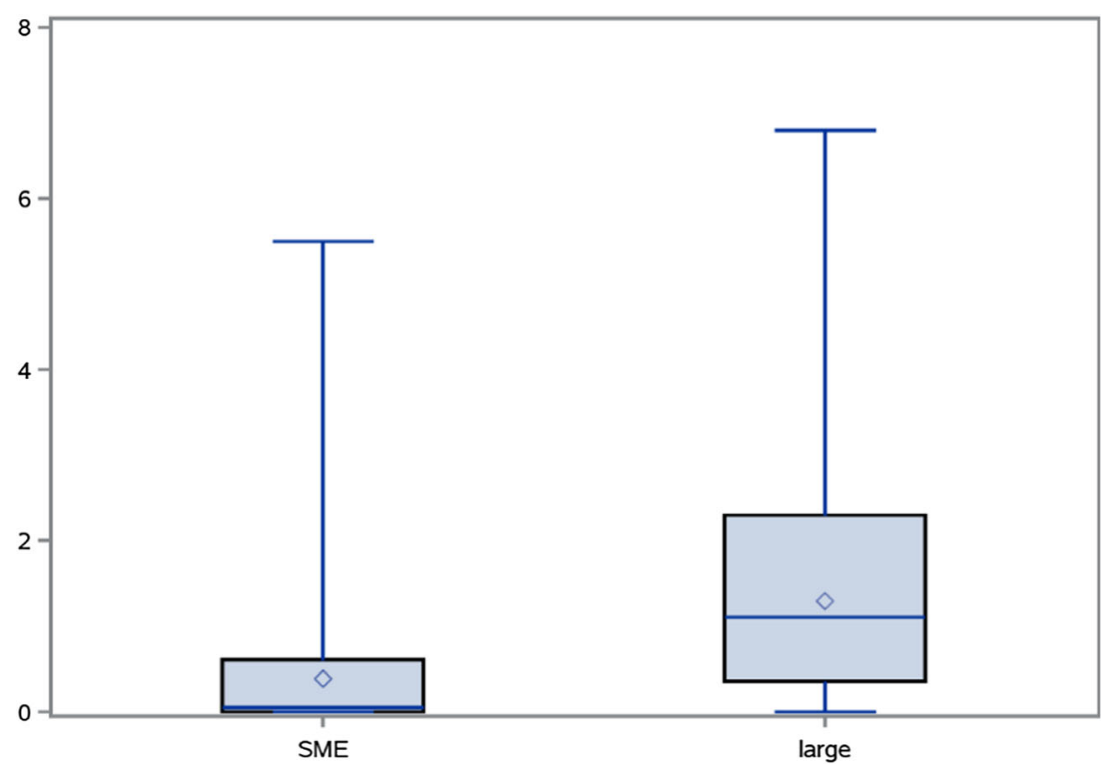


Fig. 9 Distribution of the CMDI by country

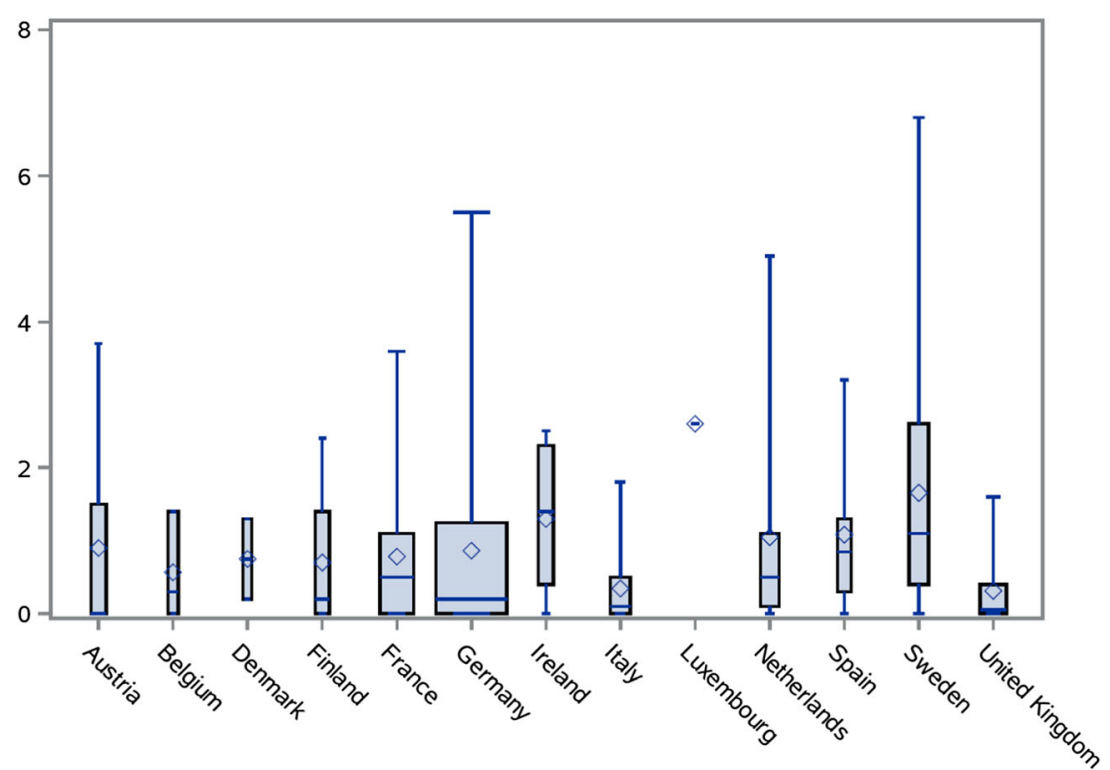

into the group labeled "small countries." As we already observed for the EDPI, we cannot identify spectacular differences among the countries in terms of CMDI performance. The companies achieve mean scores in a range between 0.4 and 1.6, with the exception of two countries. Of the two exceptions with higher means, we ignore Luxembourg because the sample contains only one company from this country. Hence, further analysis is focused on the Swedish companies. As shown in Fig. 10, the Swedish companies reach a mean value that is slightly above the value range of the other countries.

The box plots of Fig. 11 and Fig. 12 depict country-specific CMDI performance separately for the large companies and the SMEs. Several interesting insights can be obtained from these graphs. First, the large companies achieve a higher CMDI performance than the SMEs in all countries. However, similar to the findings for EDPI performance, the large companies in the UK achieve only slightly higher CMDI scores than the SMEs in the UK. An overlapping area between the middle $50 \%$ boxes of the large companies and the SMEs exists for every country apart from Italy. In general, this overlapping area indicates a similarity between the large companies and SMEs in terms of the investigated index, i.e., the CMDI. Relatively large overlapping areas can be observed for Austria and Germany. Such an overlapping area does not exist for the exception, Italy; in fact, a performance gap exists between the two Italian company groups. This is supported by the fact that the mean score of the Italian SMEs is below the lowest score of the large Italian companies. A further interesting finding revealed by the charts concerns Swedish companies' top CMDI performance. It is possible to infer from the plots that the outstanding high relative CMDI performance of Swedish companies is caused mainly by large Swedish companies. Even though the SMEs from Sweden achieved high
CMDI scores, they do not outperform SMEs in the other countries and therefore make only a minor contribution.

In the context of the trial study, we observed extensive CECM information at the website of the Japanese Panasonic corporation (Thimm and Rasmussen 2019). When Panasonic's CECM disclosure is compared with the abovedescribed findings, all other sample websites fall below this benchmark. Surprisingly, even large companies of a size similar to that of Panasonic are far from the benchmark. This fact may arise from differences in environmental regulations and governmental structures between EU countries and Japan. These issues will be addressed in our future research.

As the descriptive analysis results indicate, the great majority of the sample companies achieved relatively low scores in both the combined aggregated EDPI and the CMDI. The numbers provide evidence for our general observation that information related to environmental regulations and about companies' practices in enforcing legal compliance is only rarely disclosed. We found only a couple of companies in our sample that disclosed detailed information about their compliance management practices. For example, at the website of the German company Zeiss, ${ }^{1}$ we observed a comprehensive overview of the company's approach to environmental compliance. Zeiss provides a precise description in a section entitled "Guidelines, Structures and Processes."

A few websites of the study sample contained information that is directly related to inherent CECM responsibilities. This included information about hazardous materials contained in products, environmental product declaration information, and information about measures such as audits to ensure environmental compliance within the supply chain.

\footnotetext{
$\overline{1}$ https://www.zeiss.com/corporate/int/about-zeiss/responsibility/ environment.html (last accessed September 13th, 2019)
} 
Fig. 10 Distribution of the CMDI by country with grouping of small countries

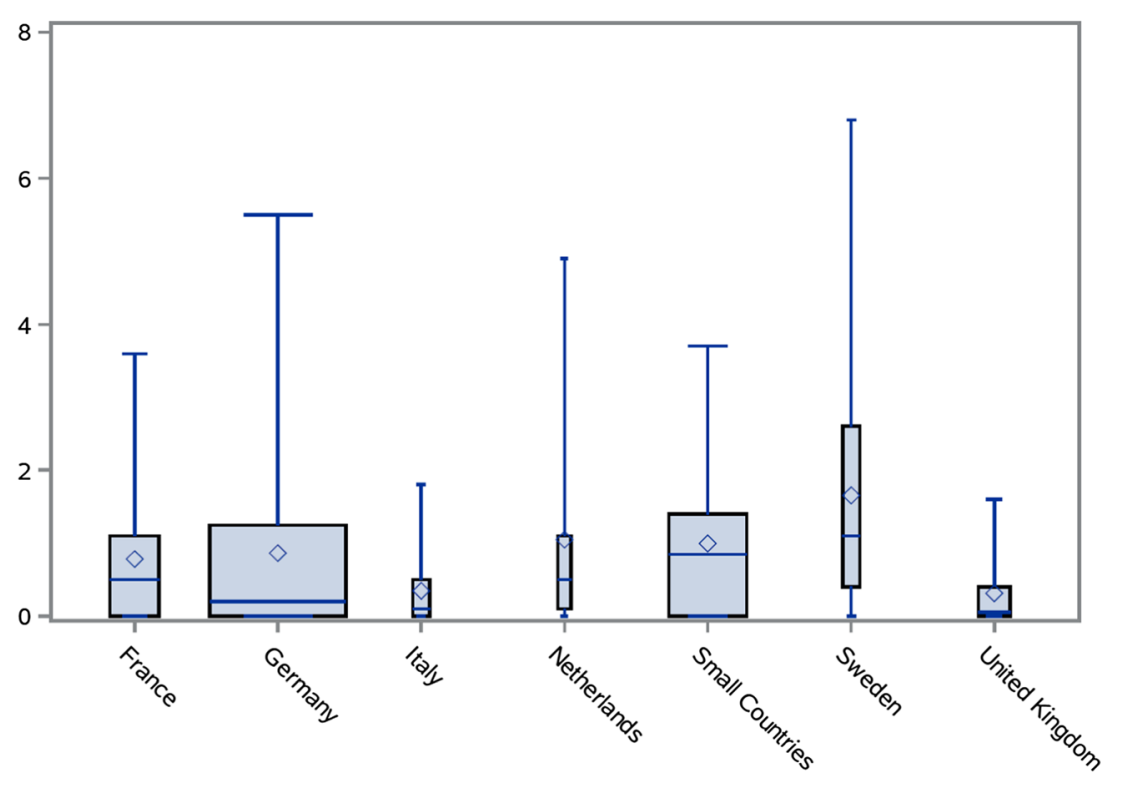

The data were also analyzed to investigate how the companies' EODI scores related to the CMDI scores. In particular, we presumed that companies with higher EODI scores would also have higher CMDI scores. However, both distributions were highly skewed, with many low scores, and did not meet the requirements of normality for further parametric analysis.

\section{Environmental dialogical communication capabilities}

As mentioned above, the EPFI measures the extent of common dialogical communication capabilities offered by websites to convey environmental engagement and to supply contact options to stakeholders. The box-and-whisker plots in Fig. 13 show the distribution of the EPFI by company size. Similar to the findings for general environmental disclosure (i.e., EDPI distribution) the data analysis revealed that the extent of dialogical communication capabilities (i.e., EPFI) is also largely determined by the size of the company.

The distribution of the EPFI by country is shown in Fig. 14. A comparison with the distribution of the EDPI by country (see Fig. 4) reveals a strong similarity between the two indices. The same countries that have a high EPFI have a high EDPI, and countries with a low EPFI also have a low EDPI. The similarity of the two indices in terms of distribution by country was also confirmed by the deeper analyses of this distribution, which are described above in the context of the EDPI statistics.
Fig. 11 Distribution of the CMDI by company size and country

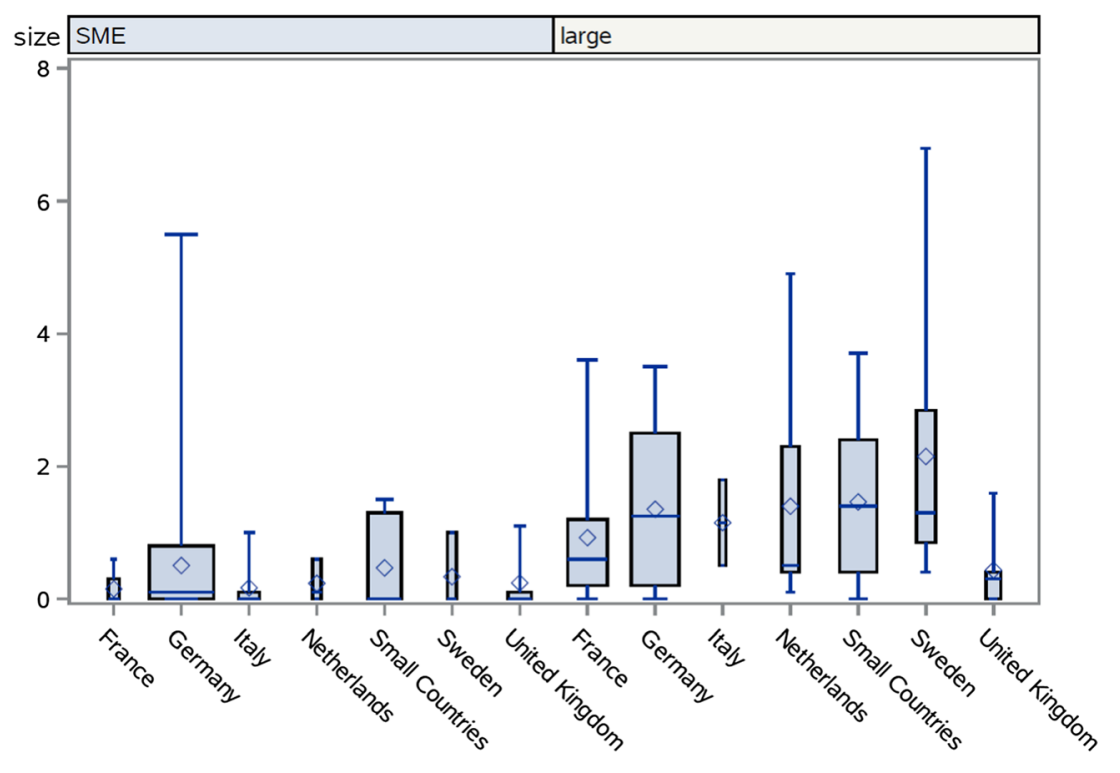


Fig. 12 Distribution of the CMDI by country and company size

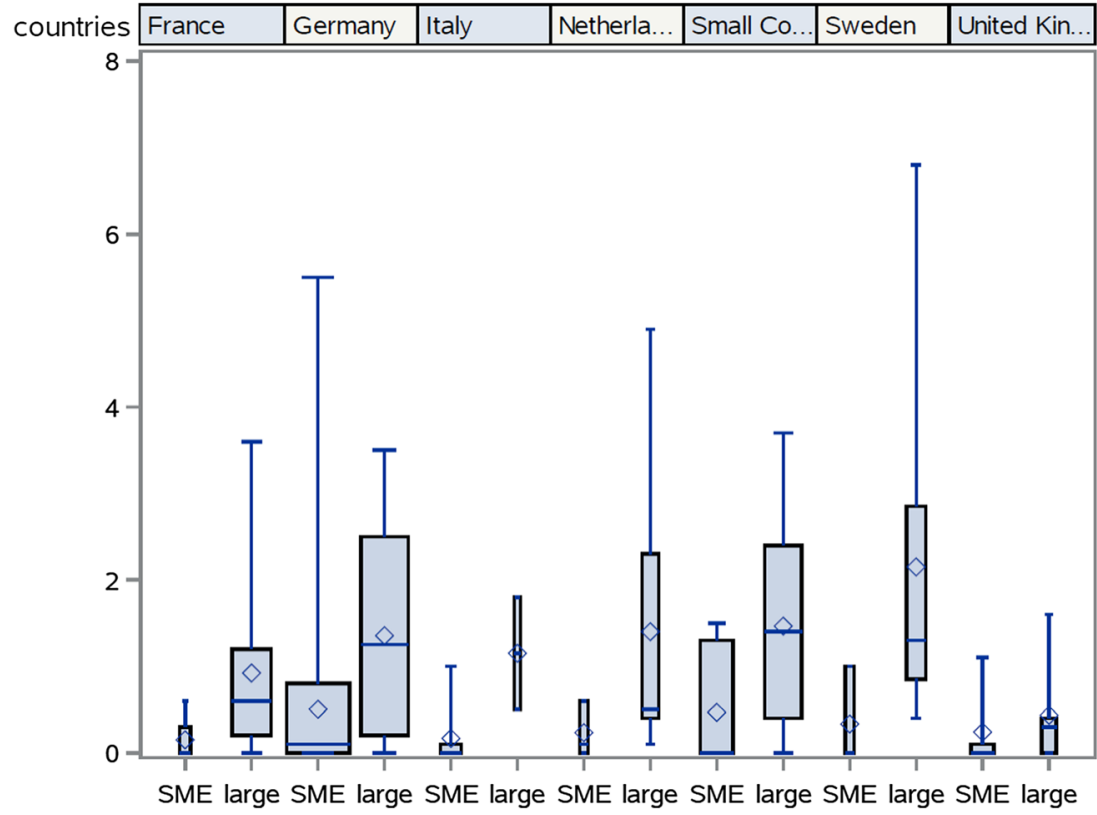

In the remainder of this section, specific selections of the dialogical communication capabilities observed in our study are further analyzed, starting with a look at the main menus of the start pages.

Table 5 contains the statistics of environmental menu items and their occurrence in the four potential menu locations on the start page for both large companies and SMEs. Note that a company may have more than one such menu item as well as more than one menu. Various empirical studies (Berthelot et al. 2013; Chaklader and Gulati 2015; Cho and Roberts 2010; Hahn and Kühnen 2013; Isenmann 2004; Jones and Alabaster 1999; Jose and Lee 2007; Kim et al. 2010; Zhang et al. 2007) have suggested that website start pages with environmental menu items are a convention of present-day environmental website disclosure practices. However, the surprisingly high number of start pages found with no relevant menu item does not support this suggestion. Although a majority of the large companies (i.e., 63) offer a start page with at least one environmental menu item, the same is true for only approximately one-third of the SMEs (i.e., 25). Additionally, we found companies with more than one environmental item: 20 large companies and 6 SMEs (for SMEs, all top and bottom) offer two menu items, and 1 large company and 0 SMEs offer three menu items (right, top, and bottom).
Fig. 13 Distribution of EPFI by company size

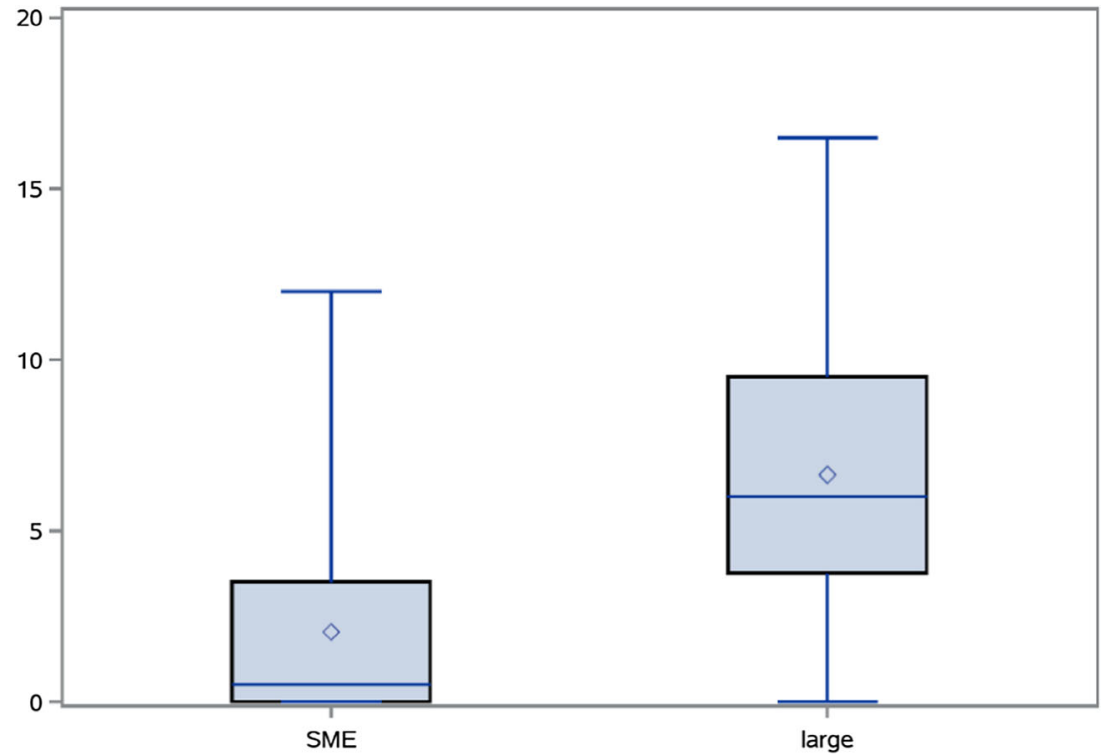


Fig. 14 Distribution of EPFI by country

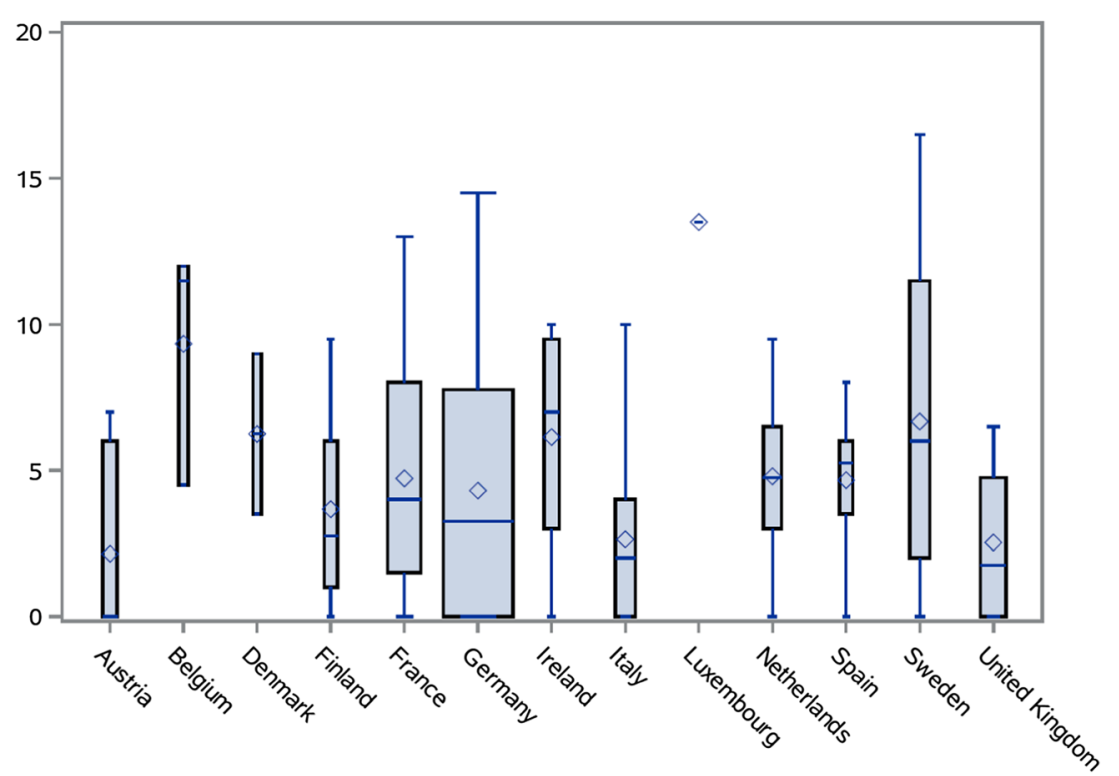

Table 6 contains the frequencies of the other dialogical communication capabilities that do not directly correspond to menus. The highest frequency of 78 occurrences was observed for environmental reports that can be downloaded from the website (P3_reports). The frequency number even amounts to $78+14=92$ when the 14 websites that offer the reports directly at the start page (F10_reports) are added. As evidenced by the statistic, downloadable reports offered by pages below the start page are provided by a large majority of the large companies but only by approximately one-fifth of the SMEs. The above-described greater general environmental disclosure efforts of large companies in comparison to SMEs may explain the relatively high frequency of the website feature of downloadable reports. Additionally, the European Union Directive 2014/95/EU (European
Commission 2014) on the disclosure of nonfinancial and diversity information may be a major reason for the popularity of online reports among large companies. The directive came into force in April 2017, and it requires capital marketoriented companies with more than 500 employees and a turnover in excess of 40 million euros or a balance sheet total of more than 20 million euros to disclose information on specific sustainability topics. Note that in some countries, such as Denmark, the Netherlands, Spain, Norway, Sweden, France, and Belgium, even before this new EU directive was implemented, companies were legally obligated to perform environmental reporting. Obviously, many of the large companies of the study sample are affected by these legal reporting obligations and might have just followed the common trend of making some version of the mandatory reports available at their websites for the general public.
Table 5 Total number of environmental menu items and location of the menu on the start page (multiple items and menus are possible for each website)

\begin{tabular}{|c|c|c|c|c|c|c|c|c|c|c|c|c|}
\hline & \multicolumn{4}{|c|}{ Number of menus } & \multicolumn{8}{|c|}{ Company size } \\
\hline & & & & & \multicolumn{4}{|c|}{ Large } & \multicolumn{4}{|c|}{ SME } \\
\hline & & & & & \multicolumn{4}{|c|}{ Number of menus } & \multicolumn{4}{|c|}{ Number of menus } \\
\hline & 0 & 1 & 2 & 3 & 0 & 1 & 2 & 3 & 0 & 1 & 2 & 3 \\
\hline & $N$ & $N$ & $N$ & $N$ & $N$ & $N$ & $N$ & $N$ & $N$ & $N$ & $N$ & $N$ \\
\hline Menu left & . & 2 & 3 & . & . & 1 & 3 & . & . & 1 & . & . \\
\hline Menu right & . & 3 & 1 & 1 & . & 2 & 1 & 1 & . & 1 & . & . \\
\hline Menu top & . & 42 & 23 & 1 & . & 29 & 17 & 1 & . & 13 & 6 & . \\
\hline Menu bottom & . & 14 & 25 & 1 & . & 10 & 19 & 1 & . & 4 & 6 & . \\
\hline Total & 66 & & 88 & & 17 & & 63 & & 49 & & 25 & \\
\hline
\end{tabular}

$N=154$ 
Table 6 Frequencies of dialogical communication capabilities that do not directly correspond to menus

\begin{tabular}{llll}
\hline Variable code & \multicolumn{2}{l}{ Size } & Total \\
\cline { 2 - 3 } & SME & Large & \\
\hline F5_news & 4 & 15 & 19 \\
P1_news & 4 & 24 & 28 \\
F6_notification & 2 & 8 & 10 \\
F7_linked_notification & 4 & 9 & 13 \\
P2_notification & 3 & 22 & 25 \\
F9_environmental_ & 10 & 35 & 45 \\
$\quad$ links & 2 & & \\
F10_reports & 16 & 62 & 14 \\
P3_reports & 1 & 2 & 78 \\
F12_training & 2 & 13 & 3 \\
P4_training & 0 & 3 & 15 \\
F13_persons & 2 & 23 & 3 \\
P5_persons & 3 & 4 & 25 \\
F13c_contact & 1 & 18 & 7 \\
P6_contact & 1 & 6 & 19 \\
F13b_blogs & 3 & 18 & 7 \\
P7_blogs & & & 21 \\
\hline
\end{tabular}

$N=154$

As the frequency data of Table 6 show, the feature of having environmental links on the start page (F9_environmental_links) seems to be another popular dialogical communication capability. Thirty-five websites of large companies and $10 \mathrm{SME}$ websites included this feature.

When we focus only on the SMEs, the frequencies for all other dialogical communication capabilities listed in Table 6 are within a low common range between 0 and 4 . For the large companies, however, these capabilities were found with higher and more distinctive frequency numbers. This finding is exemplified in the following by a discussion of two further website features that achieved relatively high frequencies among the large companies but not among the SMEs.

Our study found a relatively high frequency of dedicated environmental news sections among the websites of large companies: 15 websites with a news section directly at the start page (variable F5_news) and 24 websites with a news section at lower-level pages (variable P1_news). That large companies tend to give a relatively high priority to a specialized environmental news section may arise from their experience in the use of this website feature. Current common website practices suggest that most large companies have been gaining extensive experience in making effective use of a general news section.

For website features that allow notification of corporate environmental experts, our observation process also showed relatively high frequencies for large companies: 22 websites offered a notification function at a page somewhere below the start page with no reference from the start page (P2 notification), 9 websites had a notification function that could easily be accessed through a link from the start page to the function (F7 notification), and 8 websites included a notification function directly within the start page (F6 notification). These numbers substantiate the obvious assumption that large companies consider notification features at the corporate website to be important communication capabilities.

\section{Observed sustainability communication practices}

Many of the surveyed websites included high-level environmental policy overviews and general statements about the companies' current and planned efforts to meet the sustainable development goals (SDGs) in their environmental disclosure. At some websites, this statement was complemented by the disclosure of sustainability key performance indicators (KPIs). Even sustainability KPIs of previous years were observed at several websites (e.g., Pirelli ${ }^{2}$ and NEXANS ${ }^{3}$ ). A large majority of the companies provide the general public with downloadable extensive annual sustainability reports (several reports of more than 300 pages were found) and other annual corporate documents. Often, these reports are used as a "general container" for comprehensive and detailed environmental management information. Sometimes, the reports also include CECM information, such as Michelin's 444-page Registration Document for 2018 (Michelin 2019). The section titled (page 248) "Guaranteeing compliance with environmental management fundamentals," among others, states that in 2018, a budget of 38.6 million euro was allocated to projects to enhance the environmental performance of the production facilities.

Interestingly, for a large subset of the sample, references to the annual sustainability reports frequently occurred from other web pages with compressed sustainability content. We found html versions of the annual sustainability report only at a handful of websites (e.g., Electrolux ${ }^{4}$ ).

A focused look at more concrete environmental management disclosure subjects, such as the companies' particular challenges, environmental management practices, and environmental protection measures, suggests that companies follow different approaches. Some prefer not to disclose anything about concrete environmental subjects. When website disclosure includes concrete subjects, companies often follow one or more of the three following communication approaches. Many companies center the disclosure around their brand and/or

\footnotetext{
2 https://corporate.pirelli.com/corporate/en-ww/sustainability/mainperformance-indicators (last accessed September 13th, 2019)

${ }^{3}$ https://www.nexans.com/csr/Vision.html (last accessed September 13th, 2019)

${ }^{4}$ https://www.electroluxgroup.com/sustainabilityreports/2018/ (last accessed September 13th, 2019)
} 
products. Other companies position initiatives and measures in the foreground to reduce the ecological footprint of their production sites. For example, the website of car manufacturer Jaguar $^{5}$ pays much attention to the installation of a rooftop solar panel at one of the production sites. The third approach is to position sustainability awards and certificates at the center of website sustainability communication.

Positioning the product at the center of sustainability communication can be viewed as an obvious approach in times when individual buyers and corporate purchasers are highly concerned about the sustainability features of products and production processes. However, limiting sustainability communication to the sustainability features of products, as we observed for one German company, may be regarded by the general public as too restrictive in terms of the extent of environmental disclosure.

At several websites, the products were contextualized through topics at the center of present-day public interest, such as sustainable mobility, sustainable logistics, green urban life, sustainable buildings, and sustainable living. This contextualization included information about how to use the products in a sustainable way. For example, the environmental disclosure of Electrolux ${ }^{6}$ extensively covers the topic of "sustainable cooking." Additionally, an "ECO-Product FAQ" was observed at the website of the NXP group. ${ }^{7}$

A small number of websites provided the results of life cycle assessments (LCAs). For example, OSRAM ${ }^{8}$ s website contains LCA results for a product family. On the basis of LCA information, the UK subsidiary of the multinational cement producer CEMEX 9 described itself as a "Waste Eater" that would consume 80 times more waste than it sent to landfills.

The website of the semiconductor company STMicroelectronics ${ }^{10}$ offers information about the ecological footprint at the product category level.

The reputation management strategy of most companies seemingly does not permit the disclosure of negative sustainability information, such as missed environmental goals or the negative development of sustainability KPIs. In addition, self-

\footnotetext{
$\overline{5}$ https://media.jaguarlandrover.com/news/2014/04/jaguar-land-rover-installsuks-largest-rooftop-solar-panel-array-its-engine(last accessed September 13th, 2019)

${ }^{6}$ https://www.electroluxgroup.com/en/3-trends-from-smart-kitchen-summitthat-will-reinvent-the-cooking-journey-25743/ (last accessed September 13th, 2019)

${ }^{7}$ https://www.nxp.com/about/about-nxp/about-nxp/corporate-responsibility/ environmental-compliance-organization/eco-products-faqs:ENVIRON_ FAQ(last accessed September 13th, 2019)

${ }^{8}$ https://www.osram-group.com/en/sustainability/environmental/productlifecycle-management (last accessed September 13th, 2019)

${ }^{9}$ https://www.cemex.co.uk/-/cemex-uk-the-waste-eater-1 (last accessed September 13th, 2019)

${ }^{10} \mathrm{https} / / / \mathrm{www} . \mathrm{st} . \mathrm{com} / \mathrm{content} / \mathrm{st}$ _com/en/about/st_approach_to sustainability/sustainability-priorities/sustainable-technology/eco-design/ footprint-of-a-mems.html(last accessed September 13th, 2019)
}

critical statements seem to be rare, as they were not observed in our study, which confirms the findings of other research groups (Cho and Roberts 2010; Ding et al. 2019; Gill et al. 2008).

Our observations revealed a variety of different approaches to building and maintaining a reputation as a sustainable company. They included position statements (e.g., CEMEX's statement entitled "Environmental Management and Biodiversity"11) and video interviews of senior members about the corporate sustainability strategy (e.g., SchneiderElectric $^{12}$ ) and sustainability topics. In addition, several companies prepare and publish their own "sustainability magazines" (e.g., OSRAM ${ }^{13}$ ).

The website of Electrolux contained information about sponsoring activities at a large ecofestival. ${ }^{14}$ Furthermore, this website had a report about a free Facebook application with the name "YourWaterMark" help individuals reflect on their impact on the water supply.

The French company Legrand, ${ }^{16}$ a specialist in electrical and digital building infrastructure, published information about its participation in the "PEP ecopassport" environmental product declaration program.

In particular, for large companies, we observed a tendency to build and use custom tools that meet company-specific needs. Electrolux ${ }^{17}$ developed a so-called Environmental Performance Assessment (EPA) tool. Michelin ${ }^{18}$ established a customized indicator, the Michelin Environmental Footprint (MEFP). The CEMEX ${ }^{19}$ website mentioned that the company had developed a proprietary environmental management system (EMS) that is compatible with similar standards such as ISO 14001 and the EU Eco-Management and Audit Scheme (EMAS). It was expected that full implementation of the global EMS would be achieved in 2020.

\footnotetext{
$\overline{{ }^{11} \mathrm{https}: / / \mathrm{www}} \cdot$ cemex.com/documents/20143/160082/position-onenvironmental-management.pdf/4b034950-f322-351e-0cbb-c44f191030ae (last accessed September13th, 2019)

$12 \mathrm{https} / / / \mathrm{www}$.schneider-electric.com/en/about-us/sustainability/climatechange/ (last accessed September 13th, 2019)

${ }^{13} \mathrm{https}$ ://www.osram-group.de/en/sustainability/overview/light-issustainable (last accessed September 13th, 2019)

${ }^{14} \mathrm{https}$ ://www.electroluxgroup.com/en/electrolux-partners-withsustainability-festival-the-stockholm-act-23898/(last accessed September 13th, 2019)

${ }^{15} \mathrm{https} / / / \mathrm{www}$.electroluxgroup.com/en/as-part-of-on-going-sustainablecommitment-electrolux-unveils-yourwatermark-17073 (last accessed September 13th, 2019)

$16 \mathrm{https} / /$ www.legrand.us/resources-and-downloads/environmental-productdeclarations.aspx (last accessed September 13th, 2019)

${ }^{17} \mathrm{https}: / /$ www.electroluxgroup.com/en/environmental-policy-697/ (last accessed September 13th, 2019)

$18 \mathrm{https}$ ://www.michelin.com/en/sustainable-development-mobility/ performance-transparency/social-environmental-indicators/(last accessed September 13th, 2019)

${ }^{19} \mathrm{http}: / / \mathrm{www} 2$.cemex.com/SustainableDevelopment/ MinimizingAirEmissionsEnhancingEnvironmentalMgnt.aspx(last accessed September $13^{\text {th }}, 2019$ )
} 


\section{Conclusions}

A comprehensive empirical study of the website disclosure of environmental management and environmental compliance management at European production companies is presented in this article. The descriptive results confirm the initial assumption that companies in general refrain from a comprehensive disclosure of environmental compliance management. The data analyses reveal a relatively uniform disclosure practice in all countries of our sample except Sweden. Swedish companies publish more extensively than companies in other countries, both about engagement in general environmental management and about environmental compliance management. With respect to these two subjects, the data analyses confirmed the findings of several other research groups (Berthelot et al. 2013; Bonson and Escobar 2002; Clarkson et al. 2008; Deegan and Gordon 1996) that large companies publish more information than SMEs. The fact that large companies outperform SMEs in terms of disclosure of environmental management and environmental compliance management was observed for all countries, with one exception. According to our data, large companies from the UK disclose approximately the same amount as SMEs from the UK, and their disclosure level approximates the common SME disclosure level in Europe. A comparison between general environmental management disclosure and disclosure focused on CECM leads to another interesting insight. For all countries of our sample except the UK, the data indicate that large companies disclose far more CECM information than SMEs.

Our study contributes several new findings to the field of environmental management and environmental compliance management. It is assumed that the methodological approach of the study and, in particular, the indices defined for the data analyses provide new insight to the research community. Ideally, other research teams will be inspired to conduct similar studies, which will possibly lead to global data collection that will enable many future comparative studies, including a comparison between companies from different regions of the world.

In forthcoming research projects, data collection will be used to investigate how the environmental disclosure of companies is influenced by industry type, environmental certificates, environmental awards, and inclusion in environmental reward indices (e.g., the Dow Jones Sustainability Index (Strauss 2018)). Furthermore, the data collection will be complemented by further data about the sample companies, such as age, ownership information, and financial data. Extended data collection will be used for analyses to investigate the relationship between financial power and disclosure extent to add more recent findings to existing work on this particular research subject (Berthelot et al. 2013; Bonson and Escobar 2002; Cho and Roberts 2010; Patten and Crampton 2003). The aspect of "greenwashing" will also be incorporated into future studies. For this purpose, data about environmental incidents and environmental breaches available in governmental registers, press media, and the web will be added to the data collection. In the long run, the study will evolve into a panel by a repetition of the website observation in certain years. It is expected that the panel will reveal an evolution of corporate websites towards more disclosure of environmental management and environmental compliance management information.

Funding Open Access funding enabled and organized by Projekt DEAL.

Open Access This article is licensed under a Creative Commons Attribution 4.0 International License, which permits use, sharing, adaptation, distribution and reproduction in any medium or format, as long as you give appropriate credit to the original author(s) and the source, provide a link to the Creative Commons licence, and indicate if changes were made. The images or other third party material in this article are included in the article's Creative Commons licence, unless indicated otherwise in a credit line to the material. If material is not included in the article's Creative Commons licence and your intended use is not permitted by statutory regulation or exceeds the permitted use, you will need to obtain permission directly from the copyright holder. To view a copy of this licence, visit http://creativecommons.org/licenses/by/4.0/.

\section{References}

Aberdeen Group (2011) Compliance management in environmental, health and safety: white paper 6991. MA. Retrieved from Aberdeen Group website, Boston. http://community.dev.intelex. com/library/explore/whitepapers/aberdeen-complianceenvironment-health-and-safety. Accessed 12 Aug 2019

Alawi NAM, Massod A (2018) Environmental quality website disclosure in oil and gas sector: the case of MNCs in Yemen. ARBMS 11(1): $10-23$

Andrew J (2003) Corporate governance, the environment, and the internet. Electron Green J 1(19) Retrieved from https://escholarship.org/ uc/item/5ft9g7h2. Accessed 15 Sept 2019

Atli D (2019) An investigation of the dialogical communication capacities of Turkish GSM companies websites. IJSECSR 4(2):51-59. https://doi.org/10.4018/IJSECSR.2019070104

Berthelot S, Cormier D, Magnan M (2003) Environmental disclosure research: review and synthesis. J Account Lit 22(22):1-44

Berthelot S, Coulmont M, Thibault K (2013) Sustainability content on oil and gas company websites. BMR 2(1). https://doi.org/10.5430/bmr. v2n1p94

Bhasin ML (2012) Corporate environmental reporting on the internet: an exploratory study. Int J Manag Financ Account 4(1):78. https://doi. org/10.1504/IJMFA.2012.044838

Bonson, Escobar (2002) A survey on voluntary disclosure on the internet. Empirical evidence from 300 European Union companies. Int $\mathrm{J}$ Digit Account Res. 2(1):27-51. https://doi.org/10.4192/15778517-v2 2

Bureau van Dijk (2019) Untangling the world of private company information (White Paper). Retrieved from https://www.bvdinfo.com/engb/knowledge-base/white-papers/. Accessed 20 May 2019

Chaklader B, Gulati PA (2015) A study of corporate environmental disclosure practices of companies doing business in India. Glob Bus Rev 16(2):321-335. https://doi.org/10.1177/0972150914564430 
Chiu CL, Zhang J, Li M, Wei S, Xu S, Chai X (2020) A study of environmental disclosures practices in Chinese energy industry. AJSSR 5(1):479. https://doi.org/10.1186/s41180-020-00036-1

Cho CH, Roberts RW (2010) Environmental reporting on the internet by America's toxic 100: legitimacy and self-presentation. Int J Account Inf Syst 11(1):1-16. https://doi.org/10.1016/j.accinf.2009.12.003

Clarkson PM, Li Y, Richardson GD, Vasvari FP (2008) Revisiting the relation between environmental performance and environmental disclosure: an empirical analysis. Acc Organ Soc 33(4-5):303-327. https://doi.org/10.1016/j.aos.2007.05.003

Deegan C (2002) The legitimizing effect of social and environmental disclosures. A theoretical foundation. Account Audit Account J 15(3):282-311

Deegan C, Gordon B (1996) A study of the environmental disclosure practices of Australian corporations. Account Bus Res 26(3):187199. https://doi.org/10.1080/00014788.1996.9729510

Del Mar Alonso-Almeida M, Llach J, Marimon F (2014) A closer look at the 'global reporting initiative' sustainability reporting as a tool to implement environmental and social policies: a worldwide sector analysis. Corp Soc Responsib Environ Manag 21(6):318-335. https://doi.org/10.1002/csr.1318

Diamantopoulos A, Winklhofer H (2001) Index construction with formative indicators: an alternative to scale development. J Mark Res 38(2):269-277 Retrieved from https://www.jstor.org/stable/ 1558630 ?seq=1\#page_scan_tab_contents

Ding X, Qu Y, Shahzad M (2019) The impact of environmental administrative penalties on the disclosure of environmental information. Sustainability 11(20):5820. https://doi.org/10.3390/su11205820

Dowling J, Pfeffer J (1975) Organizational legitimacy: social values and organizational behaviour. Pac Sociol Rev 18:122-136

European Commission (2008) NACE Rev.2, Statistical Classification of Economic Activities in the European Comminity, Eurostat Methodologies and Working Papers, Luxemourg. Retrieved from https://ec.europa.eu/eurostat/documents/3859598/5902521/KSRA-07-015-EN.PDF. Accessed 15 Jan 2019

European Commission (2015) User guide to the SME definition. Publications Office, Luxembourg

European Commission, Environment and climate regional accession network (ECRAN) (2015-2016) Handbook on the Implementation of EU Environmental Legislation, European Commission, Environment and climate regional accession network (ECRAN), 2015-2016, Handbook on Edited by Hulla \& Co Human Dynamics. https://doi.org/10.2779/51324; Retrieved from http:// www.ecranetwork.org/Files/Handbook_on_Implementation_of Environmental_Legislation.pdf. Accessed 6 Feb 2019

European Commission (2014) Directive 2014/95/EU of the European parliament and of the council of 22 October 2014, Official Journal of the European Union, 15.11.2014. Retrieved from: https:/eur-lex. europa.eu/legal-content/EN/TXT/PDF/?uri=CELEX: 32014L0095\&from $=E N$. Accessed 30 June 2020

Freeman RE (2010) Strategic management. Cambridge University Press, Cambridge

Gill DL, Dickinson SJ, Scharl A (2008) Communicating sustainability: a web content analysis of North American, European and Asian firms. J Commun Manag 12(3):243-262. https://doi.org/10.1108/ 13632540810899425

Global Reporting Initiative (2015) Guidelines Part 1 reporting principles and standard disclosures. Retrieved from https://www. globalreporting.org/Pages/resource-library.aspx. Accessed 24 June 2019

Gray SJ (1988) Towards a theory of cultural influence on the development of accounting systems internationally. Abacus 1(24):1-15

Gray R, Kouhy R, Lavers S (1995) Corporate social and environmental reporting. Account Audit Account J 8(2):47-77. https://doi.org/10. 1108/09513579510146996
GSSB (2016) GRI 307: environmental compliance 2016, global sustainability standards board (GSSB). Stichting Global Reporting Initiative, Amsterdam

Hahn R, Kühnen M (2013) Determinants of sustainability reporting: a review of results, trends, theory, and opportunities in an expanding field of research. J Clean Prod 59:5-21. https://doi.org/10.1016/j. jclepro.2013.07.005

Hassan A, Hunter C, Asekomeh A (2013) GRI application levels and disclosure on specific environmental activities: an empirical investigation of industry membership and geographical region of top European companies. SEAJ 33(3):156-176. https://doi.org/10. 1080/0969160X.2013.840539

Herbst T (1998) Environmental disclosure: corporate use of the world wide web. Corp Environ Strateg 5(2):81-90. https://doi.org/10. 1016/S1066-7938(00)80071-8

Herzig C, Schaltegger S (2006) Corporate sustainability reporting. An overview. In: Schaltegger S, Bennett M, Burritt R (eds) Sustainability Accounting and Reporting. Springer Netherlands, Dordrecht, pp 301-324. https://doi.org/10.1007/978-1-4020-4974313

Ingram RW, Frazier KB (1980) Environmental performance and corporate disclosure. J Account Res 18(2):614. https://doi.org/10.2307/ 2490597

Isenmann R (2004) Internet-based sustainability reporting. IJESD 3(2): 145. https://doi.org/10.1504/IJESD.2004.004700

Isenmann R, Lenz C (2001) Customized corporate environmental reporting by internet-based push and pull technologies. Eco-manag audit 8(2):100-110. https://doi.org/10.1002/ema.153

Jensen MC, Meckling WH (1979) Theory of the firm: managerial behavior, agency costs, and ownership structure. In: Brunner K (ed) Rochester studies in economics and policy issues: Vol. 1. Economics social institutions: insights from the conferences on Analysis \& Ideology. Springer, Dordrecht, pp 163-231

Jones, K., \& Alabaster, T. (1999). Internet-based environmental reporting. Greener Management International, Taylor \& Francis Ltd. Abingdon (26), 69-90

Jose A, Lee S-M (2007) Environmental reporting of global corporations: a content analysis based on website disclosures. J Bus Ethics 72(4): 307-321. https://doi.org/10.1007/s10551-006-9172-8

Kent ML, Taylor M (1998) Building dialogic relationships through the world wide web. Public Relat Rev 24(3):321-334

Kim D, Nam Y, Kang S (2010) An analysis of corporate environmental responsibility on the global corporate web sites and their dialogic principles. Public Relat Rev 36(3):285-288. https://doi.org/10. 1016/j.pubrev.2010.04.006

Kosajan V, Chang M, Xiong X, Feng Y, Wang S (2018) The design and application of a government environmental information disclosure index in China. J Clean Prod 202:1192-1201. https://doi.org/10. 1016/j.jclepro.2018.08.056

Lodhia SK (2010) Research methods for analysing world wide web sustainability communication. SEAJ 30(1):26-36. https://doi.org/10. 1080/0969160X.2010.9651819

Marston C, Polei A (2004) Corporate reporting on the internet by German companies. Int J Account Inf Syst 5(3):285-311. https://doi.org/10. 1016/j.accinf.2004.02.009

Michelin (2019) 2018 registration document. Retrieved from Michelin website: https://www.google.com/url?sa=t\&rct=j\&q=\&esrc= s\&source=web\&cd=3\&ved=2ahUKEwjYirLfmM3kAhXHbFA ekKHXZWC0UQFjACegQIAhAC\&url=https\%3A\%2F\%2Fwww. michelin.com $\% 2$ Fen $\% 2$ Fdocuments $\% 2$ F2018-registration-document $\%$ 2F\&usg=AOvVaw2NfCybue6j8gNCDfCIZ0Zm. Accessed 21 June 2019

Mohamed Adnan S, Hay D, van Staden CJ (2018) The influence of culture and corporate governance on corporate social responsibility disclosure: a cross country analysis. J Clean Prod 198:820-832. https://doi.org/10.1016/j.jclepro.2018.07.057 
Nicolson IT (2015) Environmental audit in environmental management. In: Sarkar D, Datta R, Mukherjee A, Hannigan R (eds) An integrated approach to environmental management. John Wiley \& Sons Inc., Hoboken, pp 465-520. https://doi.org/10.1002/9781118744406. $\operatorname{ch} 20$

Patten DM, Crampton W (2002) Legitimacy and the internet: an examination of corporate web page environmental disclosures. Advances in Environmental Accounting \& Management 36(3):247-259. https://oi.org/10.1023/A:1014009229437

Patten DM, Crampton W (2003) Examination of corporate web page environmental disclosures. In: Advances in Environmental Accounting \& Management. Emerald Group publishing limited, Bingley, pp 31-57

Portella AR, Borba JA (2020) Environmental disclosure in corporate websites: a study in Brazil and USA companies. RAUSP Manag J 55(3):309-324. https://doi.org/10.1108/RAUSP-07-2018-0053

Qian W, Hörisch J, Schaltegger S (2018) Environmental management accounting and its effects on carbon management and disclosure quality. J Clean Prod 174:1608-1619. https://doi.org/10.1016/j. jclepro.2017.11.092

Ram Nidumolu C.K. Prahalad, Rangaswami MR (2009) Why sustainability is now the key driver of innovation. Harvard Business Review. (September), 1-. Retrieved from www.hbr.org. Accessed 6 Aug 2019

Rasmussen KB, Thimm H (2015) Circumventing nonresponse upgrading traditional company survey data with unobtrusive data from company websites. BMS 127(1):85-96. https://doi.org/10. $1177 / 0759106315582198$

Russo-Spena T, Tregua M, de Chiara A (2018) Trends and drivers in CSR disclosure: a focus on reporting practices in the automotive industry. J Bus Ethics 151(2):563-578. https://doi.org/10.1007/ s10551-016-3235-2

Siano A, Vollero A, Conte F, Amabile S (2017) "More than words": expanding the taxonomy of greenwashing after the Volkswagen scandal. J Bus Res 71:27-37. https://doi.org/10.1016/j.jbusres. 2016.11.002

Strauss K (2018) The world's most sustainable companies, 2018. Retrieved from Forbes website: https://www.forbes.com/sites/ karstenstrauss/2018/01/23/the-worlds-most-sustainable-companies2018/\#20fed99432b0. Accessed 18 Jan 2019

Suchman M (1995) Managing legitimacy: strategic and institutional approaches. Acad Manag Rev 20(3):571-610

Suttipun M, Stanton P (2012) A study of environmental disclosures by Thai listed companies on websites. Procedia Economics and Finance 2:9-15. https://doi.org/10.1016/S2212-5671(12)00059-7

Thimm H, Rasmussen KB (2019) Investigating website disclosure of corporate environmental compliance management. In: Schaldach
R, Simon KH, Weismüller J, Wohlgemuth V (eds) 33rd EnviroInfo Conference, Environmental Informatics Computational Sustainability: ICT Methods to achieve the UN Sustainable Development Goals. Shaker Verlag, Düren, pp 274-288

Thimm H, Rasmussen KB (2020) Disclosure of environmental compliance management on corporate websites - a literature review and future research foundation. IJSECSR 5(1):42-55. https://doi.org/10. 4018/IJSECSR.2020010103

Thimm HH, Rasmussen KB, Gohout W (2016) Website quality and performance indicators including ratio numbers - a study of German and Danish SME companies. J Bus 1(3):22. https://doi. org/10.18533/job.v1i6.39

Trabelsi S, Labelle R, Dumontier P (2008) Incremental voluntary disclosure on corporate websites, determinants and consequences. JCAE 4(2):120-155. https://doi.org/10.1016/S1815-5669(10)70032-1

Tukker A, Bennett M, Burritt RL, Jasch C, Schaltegger S (2009) Environmental management accounting for cleaner production. Eco-efficiency in industry and science, vol 24. Springer Netherlands, Dordrecht

Villiers C d, van Staden CJ (2011) Where firms choose to disclose voluntary environmental information. J Account Public Policy 30(6): 504-525. https://doi.org/10.1016/j.jaccpubpol.2011.03.005

Walden WD, Stagliano AJ (2003) AN assessment of the quality of environmental disclosure themes. In: Advances in Environmental Accounting \& Management. Emerald Group publishing limited, Bingley, pp 137-165

Wanderley LSO, Lucian R, Farache F, de Sousa Filho JM (2008) CSR information disclosure on the web: a context-based approach analysing the influence of country of origin and industry sector. $\mathrm{J}$ Bus Ethics 82(2):369-378. https://doi.org/10.1007/s10551-0089892-z

Welch TE (1998) Moving beyond environmental compliance: a handbook for integrating pollution prevention with ISO 14000. Lewis Publishers, Boca Raton, Fla. Retrieved from http://www.loc.gov/ catdir/enhancements/fy0744/97027474-d.html. Accessed 7 March 2019

Wohlin C (2014) Guidelines for snowballing in systematic literature studies and a replication in software engineering. In: Shepperd M, Hall $\mathrm{T}$, Myrtveit I (eds) Proceedings of the 18th international conference on evaluation and assessment in software engineering - EASE '14. ACM Press, New York, pp 1-10. https://doi.org/10.1145/2601248. 2601268

Works JIST (2000) NAICS desk reference: the north American industry classification system desk reference. JIST, Indianapolis

Zhang T, Gao SS, Zhang JJ (2007) Corporate environmental reporting on the web - an exploratory study of Chinese listed companies. ISEA 1(1):91. https://doi.org/10.22164/isea.v1i1.10 